\title{
Type I Interferons Act Directly on Nociceptors to Produce Pain Sensitization: Implications for Viral Infection-Induced Pain
}

\author{
ำPaulino Barragán-Iglesias, ${ }^{1,4}$ Úrzula Franco-Enzástiga, ${ }^{2}$ Vivekanand Jeevakumar, ${ }^{1}{ }^{\circledR}$ Stephanie Shiers, ${ }^{1}$ \\ Andi Wangzhou, ${ }^{1}{ }^{\oplus}$ Vinicio Granados-Soto, ${ }^{2}{ }^{\circledR}$ Zachary T. Campbell, ${ }^{3}{ }^{\mathbb{C}}$ Gregory Dussor, ${ }^{1}$ and \\ ${ }^{(1)}$ Theodore J. Price ${ }^{1}$ \\ ${ }^{1}$ School of Behavioral and Brain Sciences and Center for Advanced Pain Studies, University of Texas at Dallas, Dallas, Texas, $75080,{ }^{2}$ Department \\ of Pharmacobiology, Cinvestav, Neurobiology of Pain Laboratory, Mexico City, South Campus, Mexico, 14330, ${ }^{3}$ Department of Biological Sciences, \\ University of Texas at Dallas, Dallas, Texas, and ${ }^{4}$ Department of Physiology and Pharmacology, Center for Basic Sciences, Autonomous University \\ of Aguascalientes, Aguascalientes, Mexico, 20130
}

One of the first signs of viral infection is body-wide aches and pain. Although this type of pain usually subsides, at the extreme, viral infections can induce painful neuropathies that can last for decades. Neither of these types of pain sensitization is well understood. A key part of the response to viral infection is production of interferons (IFNs), which then activate their specific receptors (IFNRs) resulting in downstream activation of cellular signaling and a variety of physiological responses. We sought to understand how type I IFNs (IFN- $\alpha$ and IFN- $\beta$ ) might act directly on nociceptors in the dorsal root ganglion (DRG) to cause pain sensitization. We demonstrate that type I IFNRs are expressed in small/medium DRG neurons and that their activation produces neuronal hyper-excitability and mechanical pain in mice. Type I IFNs stimulate JAK/STAT signaling in DRG neurons but this does not apparently result in PKR-eIF2 $\alpha$ activation that normally induces an anti-viral response by limiting mRNA translation. Rather, type I IFNs stimulate MNK-mediated eIF4E phosphorylation in DRG neurons to promote pain hypersensitivity. Endogenous release of type I IFNs with the double-stranded RNA mimetic poly(I:C) likewise produces pain hypersensitivity that is blunted in mice lacking MNK-eIF4E signaling. Our findings reveal mechanisms through which type I IFNs cause nociceptor sensitization with implications for understanding how viral infections promote pain and can lead to neuropathies.

Key words: dorsal root ganglion; eIF4E; MNK; nociceptor; type I interferon

Significance Statement

It is increasingly understood that pathogens interact with nociceptors to alert organisms to infection as well as to mount early host defenses. Although specific mechanisms have been discovered for diverse bacterial and fungal pathogens, mechanisms engaged by viruses have remained elusive. Here we show that type I interferons, one of the first mediators produced by viral infection, act directly on nociceptors to produce pain sensitization. Type I interferons act via a specific signaling pathway (MNK-eIF4E signaling), which is known to produce nociceptor sensitization in inflammatory and neuropathic pain conditions. Our work reveals a mechanism through which viral infections cause heightened pain sensitivity

\section{Introduction}

Among the earliest symptoms of viral infection are aches and pain, effects that are usually body-wide, suggest a systemic factor as a cause. Although viral infections often cause pain that persists during the course of the ensuing illness, some viral infections, and sustained antiviral responses, can cause neuropathies leading to chronic pain (Brizzi and Lyons, 2014; Rodríguez et al., 2019).

Received Dec. 27, 2019; revised Mar. 4, 2020; accepted Mar. 19, 2020.

Author contributions: P.B.-I., V.J., V.G.-S., Z.T.C., G.D., and T.J.P. designed research; P.B.-I., U.F.-E., V.J.,

S.S., and A.W. performed research; U.F.-E., V.J., and A.W. analyzed data; P.B.-I. and T.J.P. wrote the paper.

The authors declare no competing financial interests.
For instance, HIV and herpes viruses cause painful neuropathies that can last for decades (Hadley et al., 2016; Aziz-Donnelly and Harrison, 2017). Surprisingly little is known about the mechanisms through which viruses can induce acute pain and/or lead to neuropathies. One potential mechanism is through the

This work was supported by NINDS/NIH NS065926 (T.J.P.), R01NS100788 (Z.T.C.), IBR0 through a Return Home Fellowship (P.B.-I.) and CONACyT doctoral Fellowship program (U.F.-E.). Diagrams or cartoons in Figures 7 and 8 were partially drawn using https://biorender.com/. We thank Dr. Michael ladarola (NIH) for advice on the experimental strategy using the synthetic dsRNA, poly (I:C).

Correspondence should be addressed to Theodore J. Price at theodore.price@utdallas.edu.

https://doi.org/10.1523/JNEUROSCl.3055-19.2020

Copyright $\odot 2020$ the authors 
upregulation of indoleamine 2,3 deoxygenase (IDO1) and subsequent increase in kynurenine signaling. In support of this idea, mice without the IDO1 enzyme lack hyperalgesia responses to certain viral infections (Huang et al., 2016). Another possibility is that early defense responses to viral infection trigger pain hypersensitivity. From this perspective, an ideal candidate is type I interferons (IFNs) because these cytokines are rapidly induced in a wide variety of cells on exposure to virus. These IFNs then act via their cognate receptors to induce signaling in target cells (Schreiber, 2017; Barrat et al., 2019). We hypothesized that type I IFNs might act directly on peripheral nociceptors to cause pain.

A key component of the endogenous antiviral response is induction of cellular signaling that protects cells from viral infection and prevents viral replication. This is largely mediated by gene expression regulation signaling by type I IFNs. Type I IFNs alter gene expression in target cells by binding to heterodimeric transmembrane receptors composed of IFN receptor (IFNAR) 1 and 2 subunits and then engaging downstream signaling that activates transcriptional and translational programs in target cells (Levy and Darnell, 2002; Schreiber, 2017). The canonical IFNAR signaling pathway involves activation of Janus kinase (JAK) and signal transducer and activation of transcription (STAT)-mediated changes in transcription (Levy and Darnell, 2002; de Weerd and Nguyen, 2012; Stark and Darnell, 2012). IFNAR activation also regulates translation of mRNAs through at least three pathways: (1) protein kinase $\mathrm{R}$ (PKR) driven phosphorylation of eukaryotic initiation factor $2 \alpha(\mathrm{eIF} 2 \alpha)$ causing suppression of cap-dependent translation (Pindel and Sadler, 2011; Walsh et al., 2013), (2) phosphoinositide 3 kinase (PI3K) driven activation of the mechanistic target of rapamycin complex 1 (mTORC1) pathway augmenting translation of terminal oligopyrimidine tract containing mRNAs (Thyrell et al., 2004; Hjortsberg et al., 2007), and (3) activation of extracellular signal regulated kinase (ERK) and mitogen activated protein kinase interacting kinase (MNK) signaling resulting in eIF4E phosphorylation and translation of mRNAs targeted by this phosphorylation event such as IFN stimulated genes (e.g., Isg15 and Isg54), cytokines and matrix metalloproteinases (Platanias, 2005; Sen and Sarkar, 2007; Joshi et al., 2009). MNK-eIF4E activation is engaged by type I IFNs through the canonical IFNAR-JAK signaling pathway suggesting that STAT-mediated transcriptional changes and MNK-eIF4Edriven translation changes act in concert during the endogenous antiviral response (Joshi et al., 2009). Therefore, type I IFNs produce a direct antiviral effect through PKR-mediated eIF2 $\alpha$ phosphorylation to suppress translation and block viral replication and an indirect effect via activation of MNK-eIF4E-mediated translation to augment host defense strategies such as increased immune surveillance (Joshi et al., 2009; Pindel and Sadler, 2011; Munir and Berg, 2013).

Nociceptors are tuned to detect a vast variety of immune modulators and can play a key role in host defense by responding directly to pathogenic organisms (Chiu et al., 2016; Foster et al., 2017; Pinho-Ribeiro et al., 2017). In response to pathogens or inflammatory mediators, nociceptors change their sensitivity generating nociceptive signals that act as a warning system (Liu et al., 2012; Baral et al., 2016). Overactivation of this system can lead to the generation of chronic pain disorders and damage to these neurons can cause neuropathic pain (Pinho-Ribeiro et al., 2017; Malcangio, 2019; Rodríguez et al., 2019). A key pathway linking initial nociceptor activation to nociceptor hypersensitivity and potentially the development of chronic pain is engagement of translation regulation signaling (Obara and Hunt, 2014; Khoutorsky and Price, 2018; de la Pena et al., 2019). Importantly,
eIF2 $\alpha$ phosphorylation, mTORC1 activation and MNK-eIF4E signaling can all lead to persistent sensitization of nociceptors and all of these pathways have been linked to neuropathic pain disorders (Inceoglu et al., 2015; Khoutorsky et al., 2016; Moy et al., 2017; Megat et al., 2019; Shiers et al., 2020)

We have tested the hypothesis that type I IFNs generate a pain response via a direct action on nociceptors. We find compelling evidence that exogenous and endogenous type I IFNs produce mechanical hypersensitivity via MNK-eIF4E signaling in nociceptors. This likely occurs as a downstream consequence of canonical JAK signaling. We find no evidence for engagement of PKR-eIF $2 \alpha$ signaling in nociceptors by type I IFNs. Our findings provide a mechanistic link between type I IFNs and MNKeIF4E signaling as a causative factor in pain produced by viral infection.

\section{Materials and Methods}

\section{Animals}

Male eIF4E ${ }^{\text {S209A }}$ and MNK1-/- mice were a gift of the Sonenberg laboratory at McGill University (Ueda et al., 2004; Furic et al., 2010) and bred at the University of Texas at Dallas (UTD) to generate experimental animals. Genotype was confirmed at weaning using DNA from ear clips. Experimental C57BL/6J wild-type (WT) animals were obtained from an internally maintained C57BL/6J colony at UTD. Electrophysiological experiments using WT mice were performed using mice between the ages of 4 and 6 weeks at the start of the experiment. Behavioral experiments using $e I F 4 E^{S 209 A}, M N K 1-/-($ knock-out for the Mknkl gene) and WT mice were performed using mice between the ages of 8 and 12 weeks, weighing $\sim 20-25 \mathrm{~g}$. All animal procedures were approved by the Institutional Animal Care and Use Committee at The University of Texas at Dallas and were performed in accordance with the guidelines of the International Association for the Study of Pain.

\section{Antibodies and chemicals}

Rabbit primary antibodies against p-eIF4E ${ }^{\mathrm{S} 209}$ (catalog \#ab76256, 1:500) and p-PKR (ab32036, 1:1000) were procured from Abcam. Mouse antiNeuN antibody (catalog \#MAB377; 1:500) was obtained from Millipore. Chicken (for ICC, catalog \#CPCA-Peri; 1:500) and mouse (for immunohistochemistry, catalog \#MAB1527; 1:1000) primary antibodies against peripherin were obtained from Encor Biotechnology and Sigma-Aldrich, respectively. Rabbit primary antibodies against p-JAK1 (catalog \#3331S; 1:1000), JAK1 (catalog \#3332S; 1:1000), p-STAT1 (catalog \#9171; 1:000), STAT1 (catalog \#9172S; 1:1000), p-STAT3 (catalog \#9134S; 1:1000), STAT3 (catalog \#91325; 1:1000), p-mTOR (catalog \#2976S; 1:1000), mTOR (catalog \#2983S; 1:1000), BiP (catalog \#3177; 1:1000), PKR (cata-

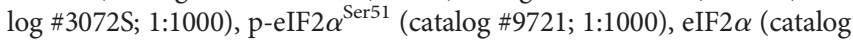
\#9722; 1:1000), p-ERK (catalog \#9101S; 1:1000), ERK (catalog \#9102S; 1:1000), p-AKT (catalog \#2965S; 1:1000), AKT (catalog \#4691S; 1:1000), p-RS6 (catalog \#2317; 1:1000), RS6 (catalog \#2317; 1:1000), eIF4E (cata$\log$ \#9742S; 1:1000), $\beta$-actin (catalog \#4967S; 1:10,000), and GAPDH (catalog \#2118; 1:10,000) were obtained from Cell Signaling Technology. AlexaFluor- and HRP-conjugated secondary antibodies were obtained from Life Technologies. The integrated stress response inhibitor, ISRIB (catalog \#SML0843), was purchased from Sigma-Aldrich. Recombinant mouse IFN- $\alpha$ protein (catalog \#12 100-1, lot \#6454) was procured from R\&D Systems. Recombinant mouse IFN- $\beta$ protein (catalog \#IF011, lot \#SLBX5164) and poly (I:C) (catalog \#P1530) were purchased from Millipore-Sigma.

\section{Primary cell culture of mouse DRG neurons and Western blot}

Cultured primary DRG neurons were used to test the effects of IFN- $\alpha$ $(300 \mathrm{U} / \mathrm{ml})$ and IFN- $\beta(300 \mathrm{U} / \mathrm{ml})$ application. For these experiments, mice were anesthetized with isoflurane and killed by decapitation. Then DRGs, from all spinal levels, were dissected and placed in chilled HBSS (Invitrogen) until processed. DRG were digested in $1 \mathrm{mg} / \mathrm{ml}$ collagenase A (Roche) for $25 \mathrm{~min}$ at $37^{\circ} \mathrm{C}$ then subsequently digested in a 1:1 mixture of $1 \mathrm{mg} / \mathrm{ml}$ collagenase $\mathrm{D}$ and papain (Roche) for $20 \mathrm{~min}$ at $37^{\circ} \mathrm{C}$. After 
this step, DRG were then triturated in a 1:1 mixture of $1 \mathrm{mg} / \mathrm{ml}$ trypsin inhibitor (Roche) and bovine serum albumin (BioPharm Laboratories), then filtered through a $70 \mu \mathrm{m}$ cell strainer (Corning). Cells were pelleted then resuspended in DMEM/F12 with GlutaMAX (ThermoFisher Scientific) containing 10\% fetal bovine serum (FBS; ThermoFisher Scientific), $5 \mathrm{ng} / \mathrm{ml} \mathrm{NGF,} 1 \%$ penicillin and streptomycin, and $3 \mathrm{mg} / \mathrm{ml} 5$-fluorouridine with $7 \mathrm{mg} / \mathrm{ml}$ uridine to inhibit mitosis of non-neuronal cells and were distributed evenly in a 6-well plate coated with poly-D-lysine (Becton Dickinson). DRG neurons were maintained in a $37^{\circ} \mathrm{C}$ incubator containing $5 \% \mathrm{CO}_{2}$ with a media change every other day. On Day 6, DRG neurons were treated with either vehicle, IFN- $\alpha$ or IFN- $\beta$ for $1,3,6$, and 24 h. Following treatments, cells were rinsed with chilled $1 \times$ PBS buffer, harvested in $200 \mu \mathrm{l}$ of RIPA lysis buffer ( $50 \mathrm{~mm}$ Tris, $\mathrm{pH} 7.4,150 \mathrm{~mm} \mathrm{NaCl}, 1 \mathrm{~mm}$ EDTA, pH 8.0, and 1\% Triton X-100) containing protease and phosphatase inhibitors (Sigma-Aldrich), and then sonicated for $5 \mathrm{~s}$. To clear debris, samples were centrifuged at $14,000 \mathrm{rpm}$ for $15 \mathrm{~min}$ at $4^{\circ} \mathrm{C}$. Ten to $15 \mu \mathrm{g}$ of protein was loaded into each well and separated by a $10 \%$ SDS-PAGE gel. Proteins were transferred to a 0.45 PVDF membrane (Millipore) at $30 \mathrm{~V}$ overnight at $4^{\circ} \mathrm{C}$. Subsequently, membranes were blocked with $5 \%$ nonfat dry milk in $1 \times$ Tris buffer solution containing Tween 20 (TTBS) for at least $2 \mathrm{~h}$. Membranes were washed three times for 10 min each $(3 \times 10)$ in $1 \times$ TTBS, then incubated with primary antibodies overnight at $4^{\circ} \mathrm{C}$. The following day, membranes were washed $3 \times 10$ each then incubated with the corresponding secondary antibodies at room temperature for $1 \mathrm{~h}$. After incubation, membranes were washed with $1 \times$ TTBS $3 \times 10$ each. Signals were detected using Immobilon Western Chemiluminescent HRP Substrate (Millipore) and then visualized with Bio-Rad ChemiDoc Touch. Membranes were stripped using Restore Western Blot Stripping buffer (ThermoFisher Scientific) and re-probed with another antibody. Analysis was performed using Image lab 6.0.1 software for Mac (Bio-Rad).

To perform Western blot analysis (WB) from tissues, animals were anesthetized with isoflurane and killed by decapitation. Lumbar spinal dorsal horn, L4-L5 DRGs and sciatic nerve were immediately frozen on dry ice and then sonicated for at least $10 \mathrm{~s}$ in $300 \mu \mathrm{l}$ of RIPA lysis buffer containing protease and phosphatase inhibitors. To clear debris, samples were centrifuged at $14,000 \mathrm{rpm}$ for $15 \mathrm{~min}$ at $4^{\circ} \mathrm{C}$. Samples were processed for WB using the experimental protocol and analysis described in this section.

\section{Immunofluorescence}

For primary neuronal cultures, DRG neurons were harvested and cultured for $6 \mathrm{~d}$ according to the protocol described above with the exception that cells were distributed evenly on poly-D-lysine-coated 8-well chamber slide with removable wells (catalog \#12-565-8, ThermoFisher Scientific). After treatments, cells were fixed in ice-cold $10 \%$ formalin in $1 \times$ PBS for $1 \mathrm{~h}$ and processed for immunocytochemistry (ICC). Cells were washed with $1 \times \mathrm{PBS}$ and permeabilized in $1 \times$ PBS containing $10 \%$ heat-inactivated normal goat serum (NGS; Atlanta Biologicals) and $0.02 \%$ Triton X-100 (Sigma-Aldrich) in $1 \times$ PBS for $30 \mathrm{~min}$ and then blocked in $10 \%$ NGS in $1 \times$ PBS for $2 \mathrm{~h}$. Primary antibodies were applied overnight at $4^{\circ} \mathrm{C}$ and the next day appropriate secondary antibodies (AlexaFluor; Invitrogen) were applied for $1 \mathrm{~h}$. After additional $1 \times$ PBS washes, coverslips were mounted on Superfrost plus slides with ProLong Gold antifade (Invitrogen). Images were taken using an Olympus FluoView 1200 confocal microscope and analyzed with FIJI for Mac OS $\mathrm{X}$. Images shown are representative of samples taken from three separate wells and presented as projections of $Z$ stacks. Using ImageJ, the corrected total cell fluorescence (CTCF) was calculated to determine the intensity of the signal between experimental groups. To do so, the integrated density and the area, as well as the background noise was measured and the CTCF calculated as equal to: the integrated density (area of selected cell $\times$ mean fluorescence of background readings). CTCF values from all experimental treatment groups were normalized to vehicle groups and expressed as normalized CTCF.

For tissues, animals were anesthetized with isoflurane and killed by decapitation, and tissues were frozen in OCT on dry ice. Spinal cords were pressure ejected using chilled $1 \times$ PBS. Sections of L4-L5 DRGs $(20 \mu \mathrm{m})$ were mounted onto Superfrost Plus slides (ThermoFisher Scientific) and fixed in ice-cold $10 \%$ formalin in $1 \times$ PBS for $1 \mathrm{~h}$ then subsequently washed $3 \times 10$ each in $1 \times$ PBS and processed for immunohistochemistry. Slides were permeabilized in $50 \%$ ethanol for $30 \mathrm{~min}$. After $30 \mathrm{~min}$, slides were washed $3 \times 10$ each in $1 \times$ PBS. Tissues were blocked for at least $2 \mathrm{~h}$ in $1 \times$ PBS and $10 \%$ NGS. Primary antibodies against NeuN, peripherin, p-eIF4 $\mathrm{E}^{\mathrm{S} 209}$ and eIF4E were applied and incubated with DRG sections on slides at $4^{\circ} \mathrm{C}$ overnight. Immunoreactivity was visualized after $1 \mathrm{~h}$ incubation with AlexaFluor secondary antibodies at room temperature. Images were taken using an Olympus FluoView 1200 confocal microscope. Images are presented as projections of $Z$ stacks, and they are representative of samples taken from three animals.

\section{Single-cell data}

Single-cell mouse DRG sequencing data from previously published work (Li et al., 2016) was used to generate Figure 2A-D. Seurat package 2.2.1 (Butler et al., 2018) was used to cluster the single-cell data and visualization (van der Maaten and Hinton, 2008).

\section{RNAscope in situ hybridization}

RNAscope in situ hybridization multiplex version 1 was performed as instructed by Advanced Cell Diagnostics (ACD). Fresh frozen lumbar DRGs from male C57BL/6J mice were rapidly dissected, frozen in cryomolds with OCT (ThermoFisher Scientific; catalog \#23-730-571) over dry ice and sectioned at $20 \mu \mathrm{m}$ onto charged slides. The sections were fixed in cold $\left(4^{\circ} \mathrm{C}\right) 10 \%$ formalin for $15 \mathrm{~min}$ and then dehydrated in $50 \%$ ethanol $(5 \mathrm{~min}), 70 \%$ ethanol $(5 \mathrm{~min})$, and $100 \%$ ethanol $(10 \mathrm{~min})$ at room temperature. The slides were air dried briefly and then boundaries were drawn around each section using a hydrophobic pen (ImmEdge PAP pen, Vector Laboratories). When hydrophobic boundaries had dried, the sections were incubated in protease IV reagent for $2 \mathrm{~min}$ and then washed in $1 \times$ PBS. Each slide was then placed in a prewarmed humidity control tray (ACD) containing dampened filter paper and incubated in a mixture of Channel 1 (Ifnar1 ACD catalog \#512971 or Ifnar2 ACD catalog \#846831), Channel 2 (Calca; ACD catalog \#417961), and Channel 3 (P2rx3; ACD catalog \#521611) probes for $2 \mathrm{~h}$ at $40^{\circ} \mathrm{C}$. This was performed one slide at a time to avoid liquid evaporation and section drying. Following probe incubation, the slides were washed two times in $1 \times$ RNAscope wash buffer and returned to the oven for $30 \mathrm{~min}$ after submersion in AMP-1 reagent. Washes and amplification were repeated using AMP-2, AMP-3, and AMP-4B reagents with a 15, 30, and $15 \mathrm{~min}$ incubation period, respectively. Slides were then washed two times in $0.1 \mathrm{M}$ phosphate buffer $(\mathrm{PB} ; \mathrm{pH} 7.4)$ and then submerged in blocking reagent (10\% NGS and $0.3 \%$ Triton-X 100 in $0.1 \mathrm{M} \mathrm{PB}$ ) for $1 \mathrm{~h}$ at room temperature. Slides were incubated in primary antibody (mouse-anti-Neurofilament 200; clone N52; Sigma-Aldrich) at 1:500 in blocking buffer overnight at $4^{\circ} \mathrm{C}$. The next day, slides were washed two times in $0.1 \mathrm{M} \mathrm{PB}$, and then incubated in secondary antibody (goat-antimouse H\&L 405; 1:2000) for $1 \mathrm{~h}$ at room temperature. Sections were washed two times in $0.1 \mathrm{M} \mathrm{PB}$, air dried, and cover-slipped with Prolong Gold Antifade (ThermoFisher Scientific; catalog \#P36930) mounting medium.

DRG sections were imaged on an Olympus FV3000 confocal microscope at $20 \times$ magnification. One image was acquired of each mouse DRG section, and three sections were imaged per mouse (total: 9 images/experiment for an $n=3$ ). The raw image files were brightened and contrasted equally in Olympus CellSens software (v1.18), and then analyzed manually one neuron at a time for expression of Ifnarl or Ifnar2 with the neuronal markers Calca (peptidergic neurons), P2rx3 (non-peptidergic neurons), and/or NF200 (A $\beta$ neurons). Soma diameter was measured using the polyline tool.

\section{Patch-clamp electrophysiology}

Cell cultures for patch-clamp electrophysiology were prepared as previously described (Moy et al., 2017). Male C57BL/6J mice (average age of $43 \mathrm{~d}$ ) were anesthetized with $5 \%$ isoflurane and killed by decapitation. DRGs were dissected and placed in ice-cold HBSS (divalent free), and incubated at $37^{\circ} \mathrm{C}$ for $15 \mathrm{~min}$ in $20 \mathrm{U} / \mathrm{ml}$ Papain (Worthington 
Biochemical) followed by $15 \mathrm{~min}$ in $3 \mathrm{mg} / \mathrm{ml}$ Collagenase type II (Worthington Biochemical). After trituration through a fire-polished Pasteur pipette of progressively smaller opening sizes, cells were plated on poly-D-lysine and laminin (Sigma-Aldrich) -coated plates. Cells were allowed to adhere for several hours at room temperature in a humidified chamber and then nourished with Liebovitz L-15 medium (Life Technologies) supplemented with $10 \%$ FBS, $10 \mathrm{~mm}$ glucose, $10 \mathrm{~mm}$ HEPES and $50 \mathrm{U} / \mathrm{ml}$ penicillin/streptomycin. The following day (within $24 \mathrm{~h}$ of dissociation), changes in neuronal excitability were tested after incubating the neurons with IFN- $\alpha(300 \mathrm{U} / \mathrm{ml})$ for $1 \mathrm{~h}$. To do so, wholecell patch-clamp experiments were performed using a MultiClamp 700B (Molecular Devices) patch-clamp amplifier and PClamp 9 acquisition software (Molecular Devices) at room temperature. Recordings were sampled at $20 \mathrm{kHz}$ and filtered at $3 \mathrm{kHz}$ (Digidata 1550B, Molecular Devices). Pipettes (outer diameter, $1.5 \mathrm{~mm}$; inner diameter, $1.1 \mathrm{~mm}$, BF150-110-10, Sutter Instruments) were pulled using a PC-100 puller (Narishige) and heat polished to 3-5 $\mathrm{M} \Omega$ resistance using a microforge (MF-83, Narishige). Series resistance was typically $7 \mathrm{M} \Omega$ and was compensated up to $60 \%$. Data were analyzed using Clampfit 10 (Molecular Devices). Data are from four independent mice cultured on separate days. The purpose of this experimental protocol was to consider both biological and experimental variability, potentially coming from the culturing process. All neurons included in the analysis had a resting membrane potential more negative than $-40 \mathrm{mV}$. The RMP was recorded 1-3 min after achieving whole-cell configuration. In currentclamp mode, cells were held at $-60 \mathrm{mV}$ and action potentials were elicited by injecting slow ramp currents from 100 to $700 \mathrm{pA}$ with $\Delta 200 \mathrm{pA}$ over $1 \mathrm{~s}$ to mimic slow depolarization. Only cells that responded to the ramp depolarization; at least one spike at the maximum $700 \mathrm{pA}$, were considered for further analysis. The pipette solution contained the following (in $\mathrm{mM}$ ): $120 \mathrm{~K}$-gluconate, $6 \mathrm{KCl}, 4 \mathrm{ATP}-\mathrm{Mg}$, $0.3 \mathrm{GTP}-\mathrm{Na}, 0.1$ EGTA, 10 HEPES, and 10 phosphocreatine, pH 7.4 (adjusted with $N$ methyl glucamine), and osmolarity was $\sim 285 \mathrm{mOsm}$. The external solution contained the following (in mM): $135 \mathrm{NaCl}, 2 \mathrm{CaCl}_{2}, 1 \mathrm{MgCl}_{2}, 5$ $\mathrm{KCl}, 10$ glucose, and 10 HEPES, pH 7.4 (adjusted with $\mathrm{N}$-methyl glucamine), and osmolarity was adjusted to $\sim 315 \mathrm{mOsm}$ with sucrose.

\section{Behavior}

Mice were housed on $12 \mathrm{~h}$ light/dark cycles with food and water available ad libitum. Mice were randomized to groups from multiple cages to avoid using mice from experimental groups that were cohabitating. Sample size was estimated by performing a power calculation using $\mathrm{G}^{\star}$ Power v3.1.9.2. With $80 \%$ power and an expectation of $d=2.2$ effect size in behavioral experiments, and $\alpha$ set to 0.05 , the sample size required was calculated as $n=6$ per group. We therefore sought to have at least $n=6$ sample in all behavioral experiments. SD (set at 0.3 ) for the power calculation was based on previously published mechanical threshold data from our laboratory (Moy et al., 2017). Animals were habituated for $1 \mathrm{~h}$ to clear acrylic behavioral chambers before beginning the experiment. For intraplantar injections, drugs were injected in a total volume of $25 \mu \mathrm{l}$ through a 30-gauge needle. For intraperitoneal injections, drugs were administered in a volume of $100 \mu \mathrm{l}$. Mechanical paw withdrawal thresholds in mice were measured using the up-down method (Chaplan et al., 1994) with calibrated von Frey filaments (Stoelting). Thermal latency was measured using a Hargreaves device (IITC Life Science; Hargreaves et al., 1988) with heated glass settings of $29^{\circ} \mathrm{C}, 40 \%$ active laser power, and $20 \mathrm{~s}$ cutoff were used. The experimenter was blinded to the genotype of the mice and the drug condition in all experiments.

\section{Quantification and statistical analysis}

All results are presented as the mean \pm SEM. Statistical differences between two groups were determined by the Student's $t$ test. One- or two-way ANOVA, followed by Dunnett or Bonferroni test, was used to compare differences between $>2$ groups. Post hoc testing for electrophysiology data used Fisher's LSD test. Differences were considered to reach statistical significance when $p<0.05$. Complete statistical analysis is detailed on Table 1 . The $N$ for each individual experiment is described in the figure legends. Data analysis was performed using GraphPad Prism 8.0 (GraphPad Software).
Data and code availability

The data that support the findings of this study, including specific details of how tSNE plots were generated, are available from the corresponding author on reasonable request.

\section{Results}

\section{Characterizing pain behavior responses induced by peripheral administration of type I IFNs}

We first sought to investigate the nociceptive responses produced by type I interferons ( $\alpha$ and $\beta$ ) in vivo in both sexes. The dose (300 U - 5 ng) of IFNs was chosen based on previous studies showing concentration-dependent effects on cellular signaling pathways (Larner et al., 1986; Hilkens et al., 2003) and studies showing plasma levels of type I IFNs in mice in response to viral infection ( $\sim 1-2 \mathrm{ng} / \mathrm{ml}$; Gerlach et al., 2006; Shibamiya et al., 2009; Murray et al., 2015; Cheng et al., 2017). In male mice, intraplantar administration of either IFN- $\alpha$ (300 U/25 $\mu \mathrm{l})$ or IFN- $\beta(300 \mathrm{U} / 25 \mu \mathrm{l})$, but not vehicle (saline), produced a rapid mechanical hypersensitivity, lasting for at least $3 \mathrm{~d}$, to von Frey filament stimulation (Fig. $1 A, B$ ) with no significant changes in paw withdrawal latency to thermal stimulation (Fig. 1C,D). Likewise, in female mice, intraplantar administration of either IFN- $\alpha(300 \mathrm{U} / 25 \mu \mathrm{l})$ or IFN- $\beta(300 \mathrm{U} / 25 \mu \mathrm{l})$ also increased hindpaw mechanical hypersensitivity (Fig. $1 E, F$ ) with no significant changes in thermal hypersensitivity (Fig. $1 G, H$ ). No sex differences in the development of mechanical hypersensitivity (Fig. $1 I, J)$ or the presence of thermal hypersensitivity (Fig. $1 K, L$ ) were observed versus female mice following either IFN- $\alpha$ (300 U/ $25 \mu \mathrm{l})$ or IFN- $\beta(300 \mathrm{U} / 25 \mu \mathrm{l})$ intraplantar administration. Because we did not find any differences in pain responses between males and females, we decided to use only males for all the subsequent experiments. These results show that activation of IFNRs by IFN- $\alpha$ or IFN- $\beta$ creates a pro-nociceptive state that is likely produced via a peripheral site of action.

\section{Identifying IFNRs expression in sensory neurons and their downstream signaling pathways}

Because we observed a pro-nociceptive effect of IFN- $\alpha$ and IFN$\beta$, we investigated the expression of IFNRs in DRG neurons. We used mouse DRG deeply RNA sequenced single cell data generated by Li et al. (2016). We generated tSNE plots to show genes expression in specific clusters of cells (van der Maaten and Hinton, 2008). IFN- $\alpha$ and IFN- $\beta$ bind a heterodimeric transmembrane receptor termed the IFN- $\alpha$ receptor (IFNAR), which is composed of IFNAR1 and IFNAR2 subunits (Schreiber, 2017). We observed expression of both Ifnarl [interferon receptor 1 (IFNR1)] and Ifnar2 (IFNR2) mRNAs with the neuronal marker rbfox3 $(\mathrm{NeuN})$, indicating their presence in neuronal populations in the mouse DRG (Fig. 2A). Ifnar1 and Ifnar2 mRNAs were coexpressed among neurons that are likely to be nociceptors because they also express Prph (peripherin) and Scn10a (Nav1.8; Fig. 2B). Additionally, we detected that Ifnar1 and Ifnar2 mRNAs are widely distributed across nociceptors of peptidergic [Trpv1 (TRPV1), Calca (CGRP)] and non-peptidergic [P2rx3 (P2X3)] nature (Fig. 2C). Ifnar2 mRNA shows higher expression levels than Ifnar1 in neurons containing F2rl1 (PAR2) and Nppb (NPPB) mRNAs (Fig. 2D)

To confirm the presence of IFNAR1 and IFNAR2 subunits in the DRG, we performed RNAscope in situ hybridization. We found that both Ifnr1 and Ifnr2 mRNAs are widely expressed in neurons expressing Calca mRNA, P2rx3 mRNA, and NF200 protein (Fig. 2E). Coexpression analysis demonstrated that 
Table 1. Student's $t$ test and one- or two-way ANOVA with their respective post hoc comparisons for each figure

\begin{tabular}{|c|c|c|}
\hline Figure & Test & Post hoc comparison \\
\hline $1 A$ & $\begin{array}{l}\text { Two-way RM ANOVA: } \\
\text { Interaction: } F_{(6,114)}=3.367, p=0.0043 \\
\text { Time effect: } F_{(6,114)}=5.570, p<0.0001 \\
\text { Treatment effect: } F_{(1,19)}=29.53, p<0.0001\end{array}$ & Bonferroni's test: Vehicle $\times$ IFN- $\alpha$ at $3 \mathrm{~h}: p<0.0001$, at $24 \mathrm{~h}: p=0.003$, at $3 \mathrm{~d}: p=0.0004$ \\
\hline $1 B$ & $\begin{array}{l}\text { Two-way RM ANOVA: } \\
\text { Interaction: } F_{(6,114)}=2.908, p=0.0112 \\
\text { Time effect: } F_{(6,114)}=3.223, p=0.0058 \\
\text { Treatment effect: } F_{(1,19)}=63.79, p<0.0001\end{array}$ & $\begin{array}{l}\text { Bonferroni's test: Vehicle } \times \text { IFN- } \beta \text { at } 1 \mathrm{~h}: p=0.0007 \text {, at } 3 \mathrm{~h}: p<0.0001 \text {, at } 24 \mathrm{~h}: p<0.0001 \text {, at } 3 \mathrm{~d} \text { : } \\
\quad p<0.0001 \text {, at } 6 \mathrm{~d}: p=0.0006\end{array}$ \\
\hline $1 E$ & $\begin{array}{l}\text { Two-way RM ANOVA: } \\
\text { Interaction: } F_{(6,60)}=3.453, p=0.0054 \\
\text { Time effect: } F_{(6,60)}=7.657, p<0.0001 \\
\text { Treatment effect: } F_{(1,10)}=29.05, p=0.0003\end{array}$ & Bonferroni's test: vehicle $\times$ IFN- $\alpha$ at $1 \mathrm{~h}: p=0.0002$, at $3 \mathrm{~h}: p=0.0430$, at $24 \mathrm{~h}: p=0.0018$, at $3 \mathrm{~d}: p=0.002$ \\
\hline $1 F$ & $\begin{array}{l}\text { Two-way RM ANOVA: } \\
\text { Interaction: } F_{(6,60)}=3.569, p=0.0043 \\
\text { Time effect: } F_{(6,60)}=6.728, p<0.0001 \\
\text { Treatment effect: } F_{(1,10)}=42.45, p<0.0001\end{array}$ & Bonferroni's test: vehicle $\times$ IFN- $\beta$ at $1 \mathrm{~h}: p=0.0109$, at $3 \mathrm{~h}: p<0.0001$, at $24 \mathrm{~h}: 0.0037$, at $3 \mathrm{~d}: p=0.0032$ \\
\hline $3 A$ & $\begin{array}{l}\text { Ordinary one-way ANOVA: } \\
\text { IFN- } \alpha \\
\text { pJAK: } F_{(3,8)}=5.088, p=0.0293 \\
\text { pSTAT1: } F_{(3,8)}=30.42, p=0.0001 \\
\text { STAT1: } F_{(3,8)}=11.71, p=0.0027 \\
\text { p-STAT3: } F_{(3,8)}=5.298, p=0.0264 \\
\text { IFN- } \beta \\
\text { pJAK: } F_{(3,20)}=3.614, p=0.0311 \\
\text { pSTAT1: } F_{(3,8)}=6.424, p=0.0159 \\
\text { STAT1: } F_{(3,8)}=13.7, p=0.0016 \\
\text { p-STAT3: } F_{(3,8)}=9.089, p=0.0059\end{array}$ & $\begin{array}{l}\text { Dunnett's test: } \\
\text { IFN- } \alpha \\
\text { Vehicle } \times \text { IFN- } \alpha \text { at } 1 \mathrm{~h}: p=0.0163 \text {, at } 3 \mathrm{~h}: 0.0473 \\
\text { Vehicle } \times \text { IFN- } \alpha \text { at } 1 \mathrm{~h}: p<0.0001 \\
\text { Vehicle } \times \mathrm{IFN}-\alpha \text { at } 6 \mathrm{~h}: p=0.0036 \\
\text { Vehicle } \times \mathrm{IFN}-\alpha \text { at } 1 \mathrm{~h}: p=0.0281 \\
\mathrm{IFN}-\beta \\
\text { Vehicle } \times \mathrm{IFN}-\beta \text { at } 1 \mathrm{~h}: p=0.0190 \\
\text { Vehicle } \times \mathrm{IFN}-\beta \text { at } 1 \mathrm{~h}: p=0.0134 \\
\text { Vehicle } \times \mathrm{IFN}-\beta \text { at } 6 \mathrm{~h}: p=0.0010 \\
\text { Vehicle } \times \mathrm{IFN}-\beta \text { at } 1 \mathrm{~h}: 0.0074\end{array}$ \\
\hline $3 C$ & $\begin{array}{l}\text { Ordinary one-way ANOVA: } \\
\text { IFN- } \alpha \\
\text { p-ERK: } F_{(3,15)}=13.39, p=0.0002 \\
\text { p-elF4E: } F_{(3,8)}=17.29, p=0.0007 \\
\text { pAKT: } F_{(3,20)}=29.26, p<0.0001 \\
\text { IFN- } \beta \\
\text { p-ERK: } F_{(3,20)}=13.99, p<0.0001 \\
\text { p-elF4E: } F_{(3,20)}=1.894, p=0.1631 \\
\text { pAKT: } F_{(3,20)}=3.847, p=0.0253\end{array}$ & $\begin{array}{l}\text { Dunnett's test: } \\
\text { IFN- } \alpha \\
\text { Vehicle } \times \text { IFN- } \alpha \text { at } 1 \text { h: } 0.0119 \\
\text { Vehicle } \times \text { IFN- } \alpha \text { at } 1 \text { h: } 0.0011 \\
\text { Vehicle } \times \text { IFN- } \alpha \text { at } 1 \text { h: } 0.0001 \text {, at } 3 \text { h: } 0.0001 \text {, at } 6 \text { h: } 0.0337 \\
\text { IFN- } \beta \\
\text { Vehicle } \times \text { IFN- } \beta \text { at } 1 \mathrm{~h}: p=0.0109 \\
\text { Vehicle } \times \text { IFN }-\beta \text { at } 1 \mathrm{~h}: p=0.0343 \\
\text { Vehicle } \times \text { IFN- } \beta \text { at } 1 \text { h: } 0.0168\end{array}$ \\
\hline $5 C$ & Ordinary two-way ANOVA: & Uncorrected Fisher's LSD. Control vs IFN- $\alpha$ at $300 \mathrm{pA}: p=0.0127$, at $500 \mathrm{pA}: p=0.0053$, at $700 \mathrm{pA}: p=0.0045$ \\
\hline
\end{tabular}

Uncorrected Fisher's LSD: Control vs IFN- $\alpha$ at $100 \mathrm{pA}: p=0.0054$, At $300 \mathrm{pA}: p=0.0203$, at $700 \mathrm{pA}: p=0.0498$

Dunnett's test. Vehicle $\times$ IFN- $\alpha: p=0.0002$; vehicle $\times$ IFN $-\beta: p=0.0001$

Bonferroni's test. WT + IFN- $\alpha \times \mathrm{MNK}^{-1-}+\mathrm{IFN}-\alpha$ at $1 \mathrm{~h}: p=0.0155$, at $3 \mathrm{~h}: p=0.0055$, at $24 \mathrm{~h}: p=0.0106$, at $3 \mathrm{~d}: p=0.0007$

Bonferroni's test. WT + IFN- $\beta \times$ MNK1 $^{-1-}+$ IFN- $\beta$ at 3 h: $p=0.0009$, at 24 h: $p=0.0160$, at $3 \mathrm{~d}: p=0.0008$

Bonferroni's test. WT $+\mathrm{IFN}-\alpha \times$ elF4E ${ }^{\mathrm{S209A}}+\mathrm{IFN}-\alpha$ at $1 \mathrm{~h}: p=0.0053$, at $3 \mathrm{~h}: 0.0047$, at $3 \mathrm{~d}: p=0.0384$

Bonferroni's test. WT + IFN- $\beta \times$ elF4E $2209 \mathrm{~A}-1-+$ IFN- $\beta$ at $3 \mathrm{~h}: p=0.009$, at $24 \mathrm{~h}: p=0.00,41$ at $3 \mathrm{~d}$ : $p=0.0006$ 
Table 1. Continued

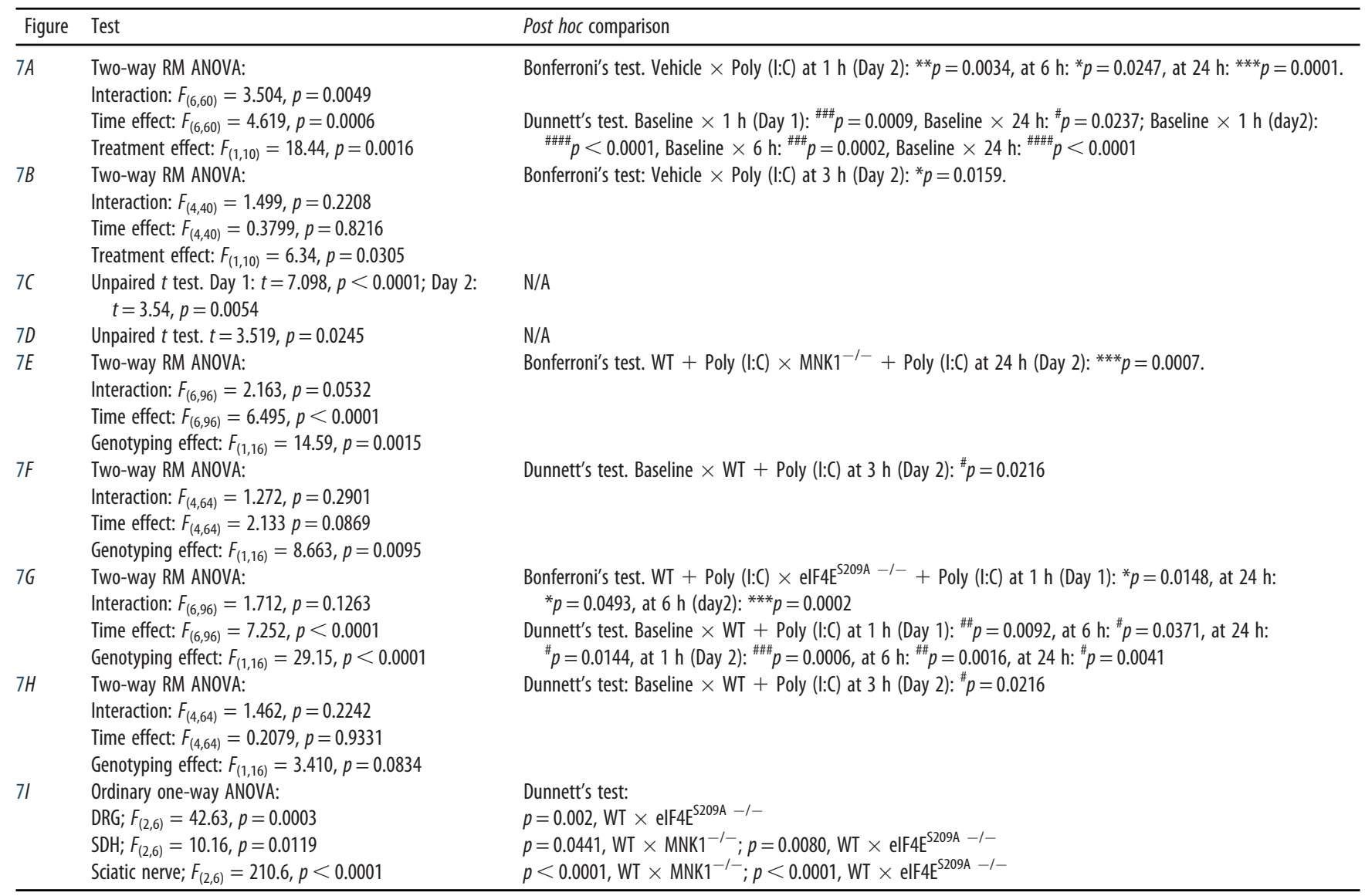

Ifnar 1 and Ifnar2 show a similar pattern of expression across peptidergic nociceptors (Calca+) and large diameter neurons $(\mathrm{NF} 200+)$. However, Ifnar 1 is more expressed than Ifnar2 in non-peptidergic $(P 2 r \times 3+)$ nociceptors $(35.8 \%$ vs $26.5 \%$; Fig. $2 F, G)$. Additionally, $\sim 80-90 \%$ of total neurons in the DRG express Ifnar 1 and Ifnar2 (Fig. $2 H$, and $E-G$ ). Coexpression analysis based on neuronal size confirmed that both Ifnarl and Ifnar2 are present across the entire neuronal population in the DRG (Fig. 2I,J). Therefore, these results confirm that IFNRs are present in mouse DRG neurons supporting the idea that their activation could modulate nociceptive signaling events.

We then sought to investigate the downstream signaling events evoked by type I IFN application to cultured DRG neurons. We focused on two major pathways involved in type I IFN signaling in different cell types: transcriptional control via JAK/ STAT (Levy and Darnell, 2002; de Weerd and Nguyen, 2012; Stark and Darnell, 2012) and translational control via two distinct pathways. Translation regulation by type I IFNs can occur through stimulation of cap-dependent translation via ERK/MAP kinase-MNK-eIF4E signaling (Walsh et al., 2013; Ivashkiv and Donlin, 2014) or inhibition of cap-dependent translation through induction of PKR-eIF $2 \alpha$ signaling (Pindel and Sadler, 2011; Walsh et al., 2013) resulting in activation of the integrated stress response (ISR). Direct application of either IFN- $\alpha(300 \mathrm{U} / \mathrm{ml})$ or IFN- $\beta(300 \mathrm{U} / \mathrm{ml})$ rapidly activated downstream JAK/STAT signaling pathways in cultured DRG neurons (Fig. 3A). This signaling cascade involved the phosphorylation of JAK1, STAT1, and STAT3 together with a delayed increase in STAT1 total protein, likely representing a transcriptional change. In addition to STATs, other signaling factors have a role in IFN- mediated activities. These include activation of the AKT/mTOR/ ULK1 pathway via PI3K and the ERK/MAP kinase pathway (Thyrell et al., 2004; Platanias, 2005; Hjortsberg et al., 2007; Saleiro et al., 2015). We did not observe any changes in mTOR or ribosomal protein S6 phosphorylation (Fig. $3 B$ ) but we did observe an increase in ERK and eIF4E phosphorylation that occurred rapidly after type I IFN exposure (Fig. 3C). Both IFN- $\alpha$ and IFN- $\beta$ also stimulated AKT phosphorylation (Fig. $3 C$ ). These findings demonstrate that type I IFNs engage cap-dependent translation regulation signaling via eIF4E phosphorylation.

Type 1 IFNs are also known to regulate translation via induction of PKR and activation of the ISR. We did not observe changes in p-PKR or p-eIF2 $\alpha$ levels and no changes were observed in $\mathrm{BiP}$ expression (ER chaperone protein) in response to type I IFN exposure (Fig. $4 A, B$ ). We noticed a non-statistically significant downregulation of $\mathrm{p}$-eIF $2 \alpha$ within the same time course of p-ERK/p-eIF4E activation (Fig. $4 A, B$ ). A possible explanation is that, as type I interferons are enhancing features of cap-dependent translation machinery, a slight downregulation in the pathway that suppresses cap-dependent translation, p-eIF2 $\alpha$, may also be occurring. Moreover, 24 h exposure to either IFN- $\alpha$ or IFN- $\beta$ did not modify PKR phosphorylation or expression suggesting that type I IFNs do not induce PKR expression in DRG neurons (Fig. 4C). In further support of these observations, no changes on $\mathrm{p}-\mathrm{PKR} / \mathrm{PKR}$ after a long IFN- $\alpha$ exposure were observed in the presence of the integrated stress response inhibitor ISRIB (Fig. 4C), and ISRIB does not suppress signaling pathways shown to be modulated by IFN $-\alpha$ or IFN- $\beta$ in our previous experiments (Fig. $4 D, E$ ). Together, these experiments demonstrate that type I IFNs engage MNK-eIF4E signaling in 
von Frey
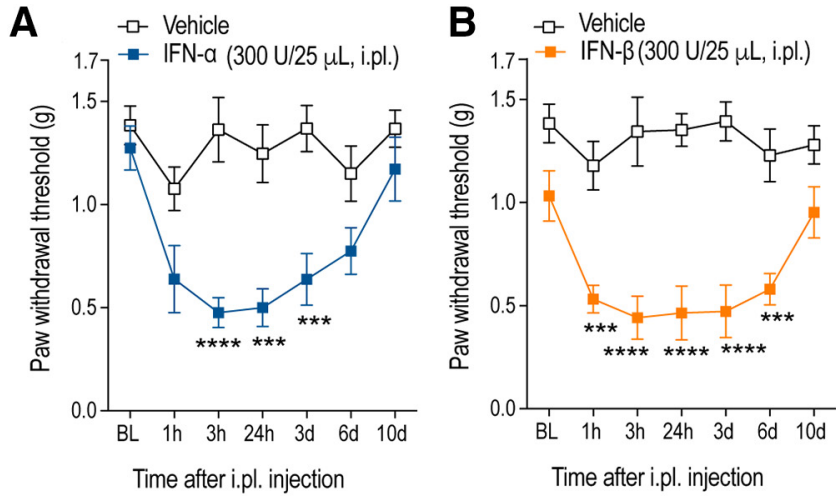

von Frey

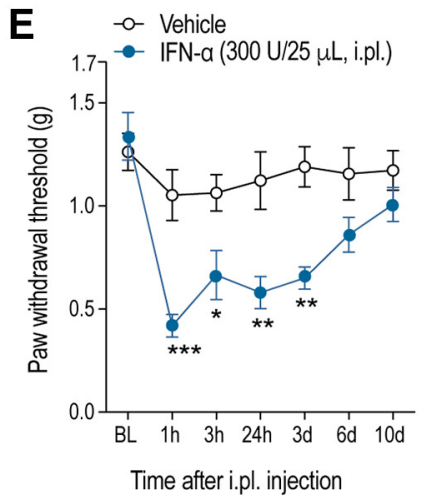

F $\quad-\infty$ vehicle

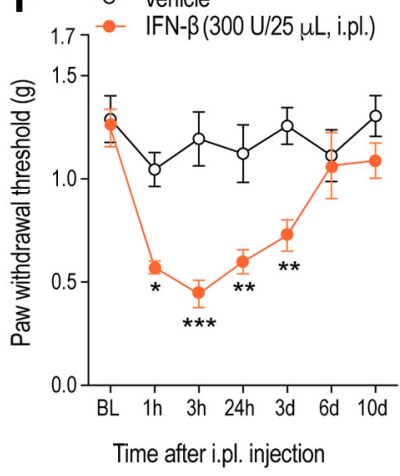

von Frey

○'
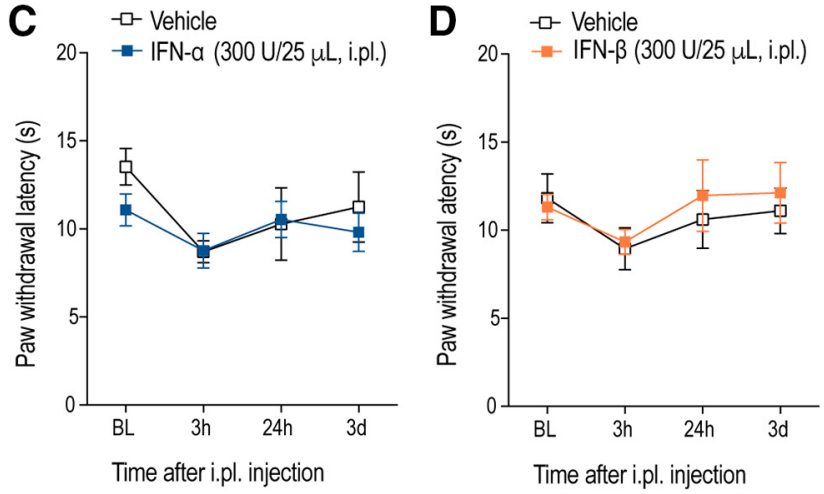

Y

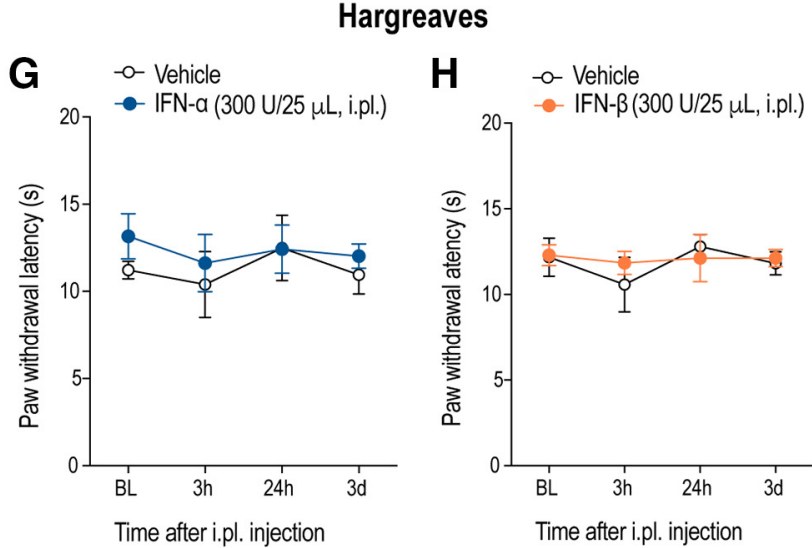

Hargreaves
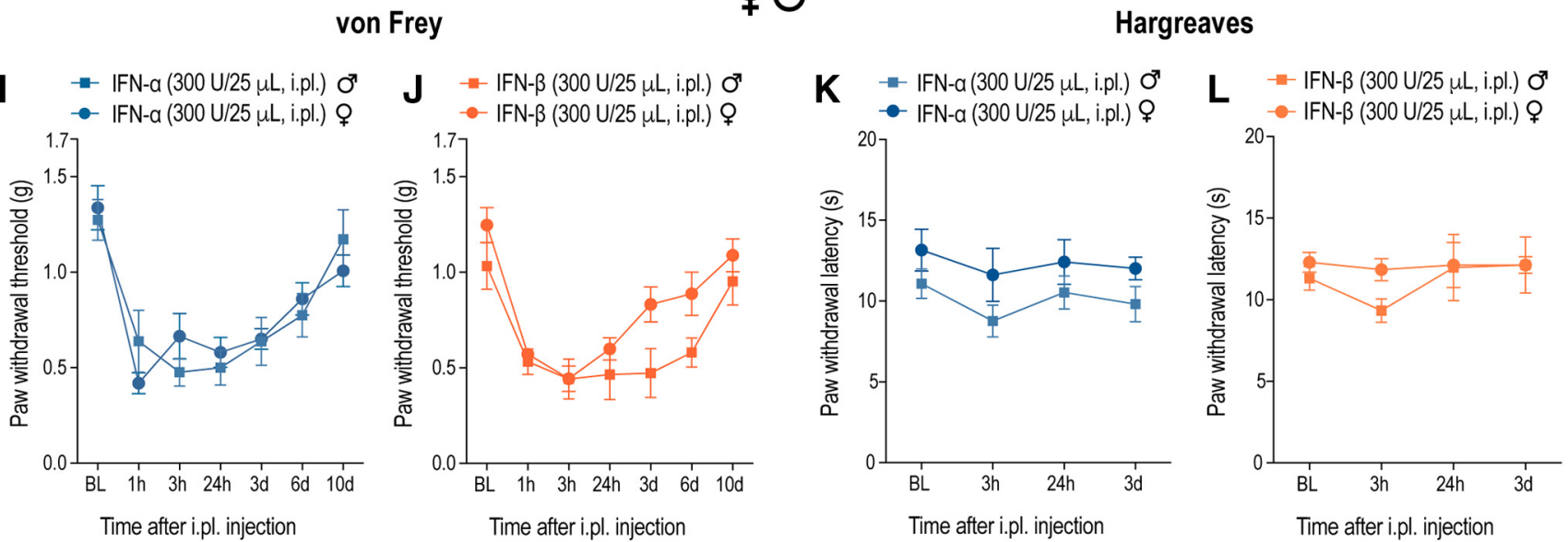

Figure 1. Type I IFNs induce mechanical nociceptive hypersensitivity responses via a peripheral action in male and female mice. $\boldsymbol{A}-\boldsymbol{D}$, In male mice, intraplantar (i.pl.) administration of IFN- $\alpha(300 \mathrm{U} / 25 \mu \mathrm{l})$ or IFN- $\beta(300 \mathrm{U} / 25 \mu \mathrm{l})$ increased paw mechanical hypersensitivity $(\mathrm{g})$ to von Frey stimulation $(\boldsymbol{A}, \boldsymbol{B})$ with no significant changes in paw withdrawal latency $(\mathrm{s})$ to thermal stimulation (C, D). $n=9$ (vehicle groups) and $n=12$ (IFN groups) in $\boldsymbol{A}$ and $\boldsymbol{B} . n=6$ (vehicle groups) and $n=12$ (IFN groups) in $\boldsymbol{C}$ and $\boldsymbol{D}$. $\boldsymbol{E}-\boldsymbol{H}$, In female mice, intraplantar administration of IFN- $\alpha(300 \mathrm{U} / 25 \mu \mathrm{l})$ and IFN- $\beta(300 \mathrm{U} / 25 \mu \mathrm{l})$ increased paw mechanical sensitivity to von Frey stimulation $(\boldsymbol{E}, \boldsymbol{F})$ with no significant changes in paw withdrawal latency (s) to thermal stimulation $(\boldsymbol{G}, \boldsymbol{H}) . n=6$ per group. $I-L$, When versus female, no significant sex differences in the development of mechanical hypersensitivity $(\boldsymbol{I}, \boldsymbol{J})$ or the presence of thermal sensitivity $(\boldsymbol{K}, \boldsymbol{L})$ were observed between groups following either IFN- $\alpha(300 \mathrm{U} / 25 \mu \mathrm{l})$ or IFN- $\beta$ (300 U/25 $\mu \mathrm{l})$ intraplantar administration. Data are presented as mean \pm SEM. Group differences were assessed using two-way ANOVA for $\boldsymbol{A}, \boldsymbol{B}$, and $\boldsymbol{E}, \boldsymbol{F}$, followed by Bonferroni's multiple-comparisons test. ${ }^{*} p<0.05,{ }^{* *} p<0.01,{ }^{* *} p<0.001,{ }^{* * *} p<0.0001$.

DRG cultures and do not induce PKR activation to suppress capdependent translation via eIF2 $\alpha$ phosphorylation.

Patch-clamp electrophysiology on DRG neurons links type I IFNs activity to neuron hyperexcitability

To assess whether the effects of type I interferons contribute to nociceptor excitability, we exposed DRG neurons to IFN- $\alpha$ (300
$\mathrm{U} / \mathrm{ml}$ ) for $\sim 1 \mathrm{~h}$ (average exposure time: $86.6 \pm 7 \mathrm{~min}$ ) and measured neuronal excitability using patch-clamp electrophysiology. The treatment was present in both the L- 15 culture medium and later in the external bath solution until completion of the electrophysiology experiments. Patch-clamp electrophysiology was performed from small- and medium-sized populations of neurons in the cultured DRGs in both groups (capacitance: control 23.8 

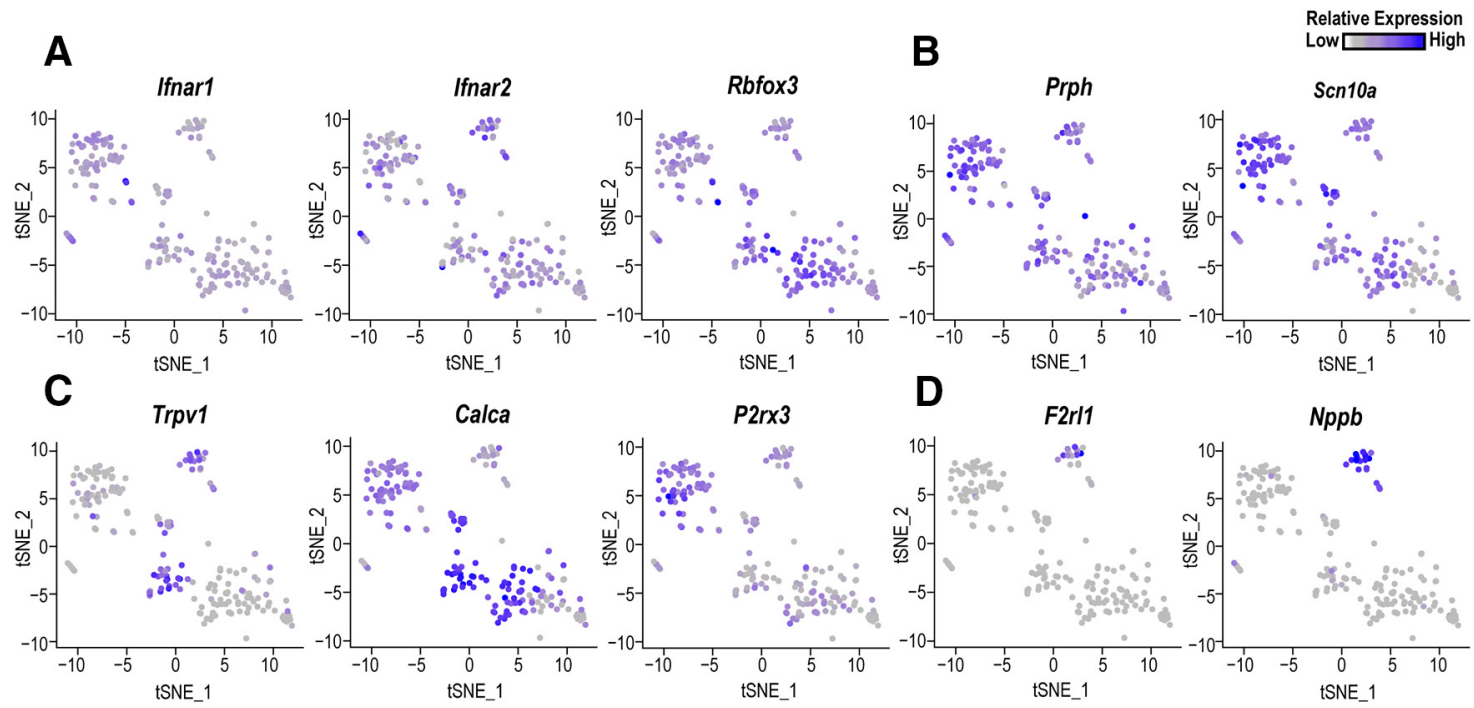

E
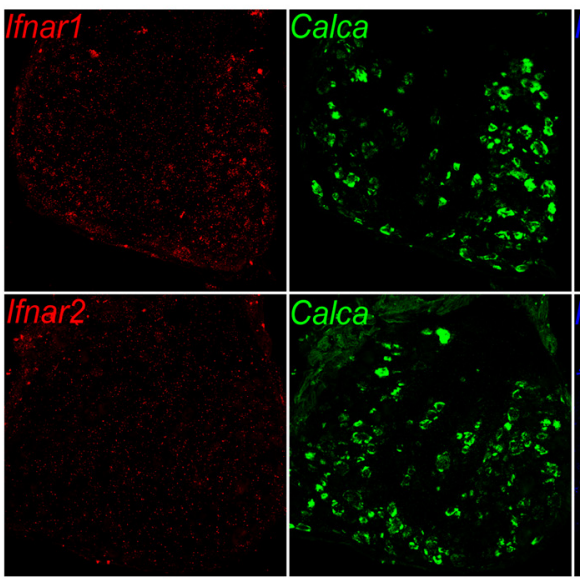

F
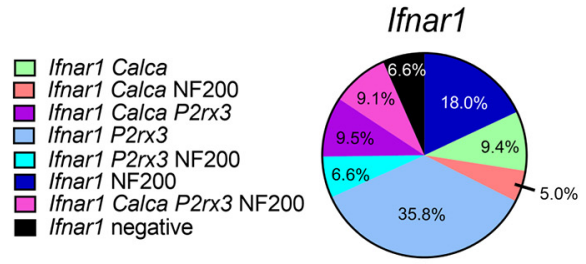

G
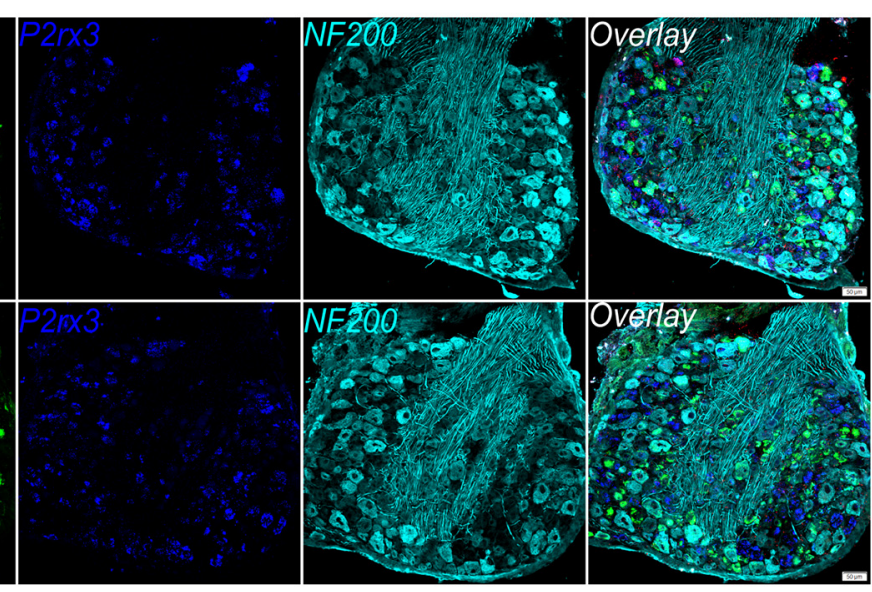

Ifnar2
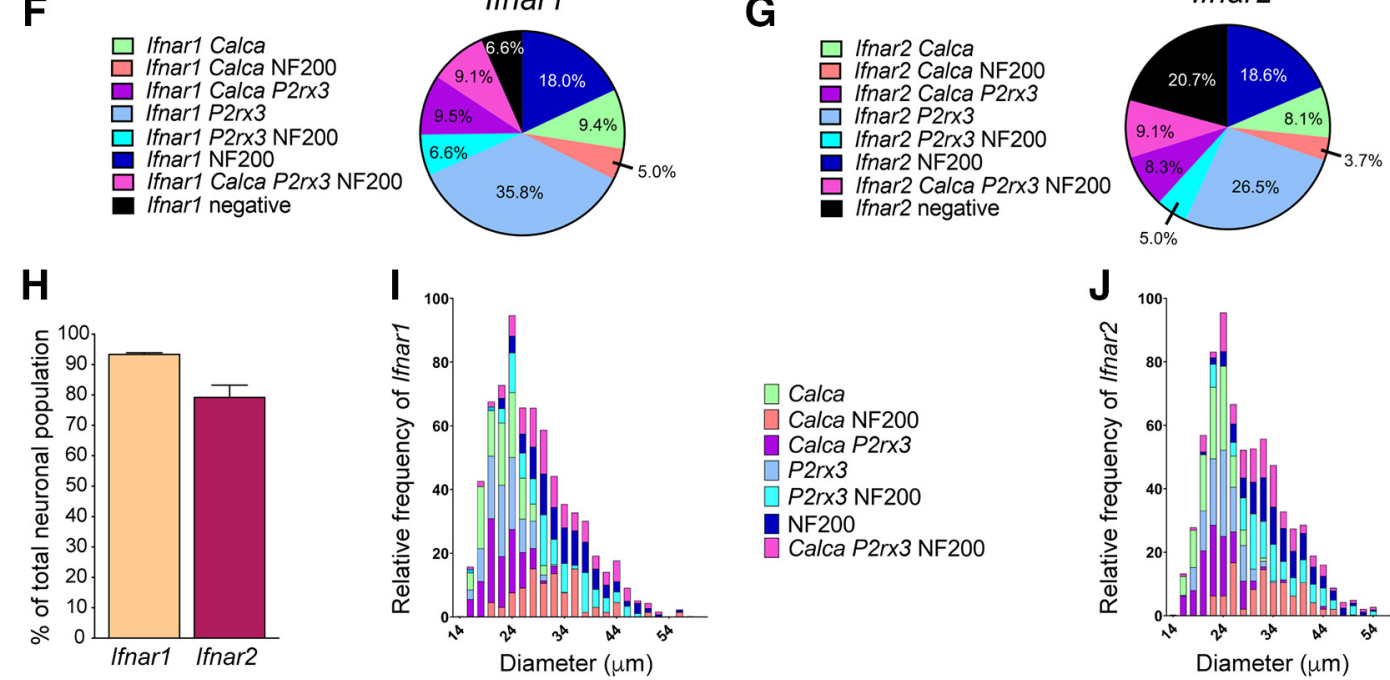

Figure 2. Expression of IFNRs in DRG sensory neurons. $\boldsymbol{A}$, Single DRG neuron-sequencing tSNE clusters showing expression of both Ifnar1 (IFNR1) and Ifnar2 (IFNR2) mRNAs with the neuronal marker rbfox3 (NeuN). B, Ifnar1 and Ifnar2 mRNAs expression overlaps with the small/medium-sized neuron subpopulation expressing Prph (peripherin) and Scn10a (Nav1.8). C, Ifnar1 and Ifnar2 mRNAs distribution across DRG sensory neurons of peptidergic [Trpv1 (TRPV1), Calca (CGRP)] and nonpeptidergic [P2rx3 (P2X3)] sub-clusters. D, Ifnar1 and Ifnar2 mRNAs expression differences in a subpopulation that express F2rl1 (PAR2) and Nppb (NPPB). $\boldsymbol{E}$, In situ hybridization of Ifnr1 and Ifnr2 (red) in neurons expressing (alca (green), P2rx3 (blue) and NF200 (cyan). F, G, Coexpression analysis of Ifnrl and Ifnr2 across the nociceptive population in the DRG. $\boldsymbol{H}$, Quantification of percentage Ifnrl and Ifnr2 mRNA subunits based on total DRG neuronal population. $n=3$. I, J, Frequency analysis of Ifnr 1 and Ifnr2 in the DRG based on neuronal size. 

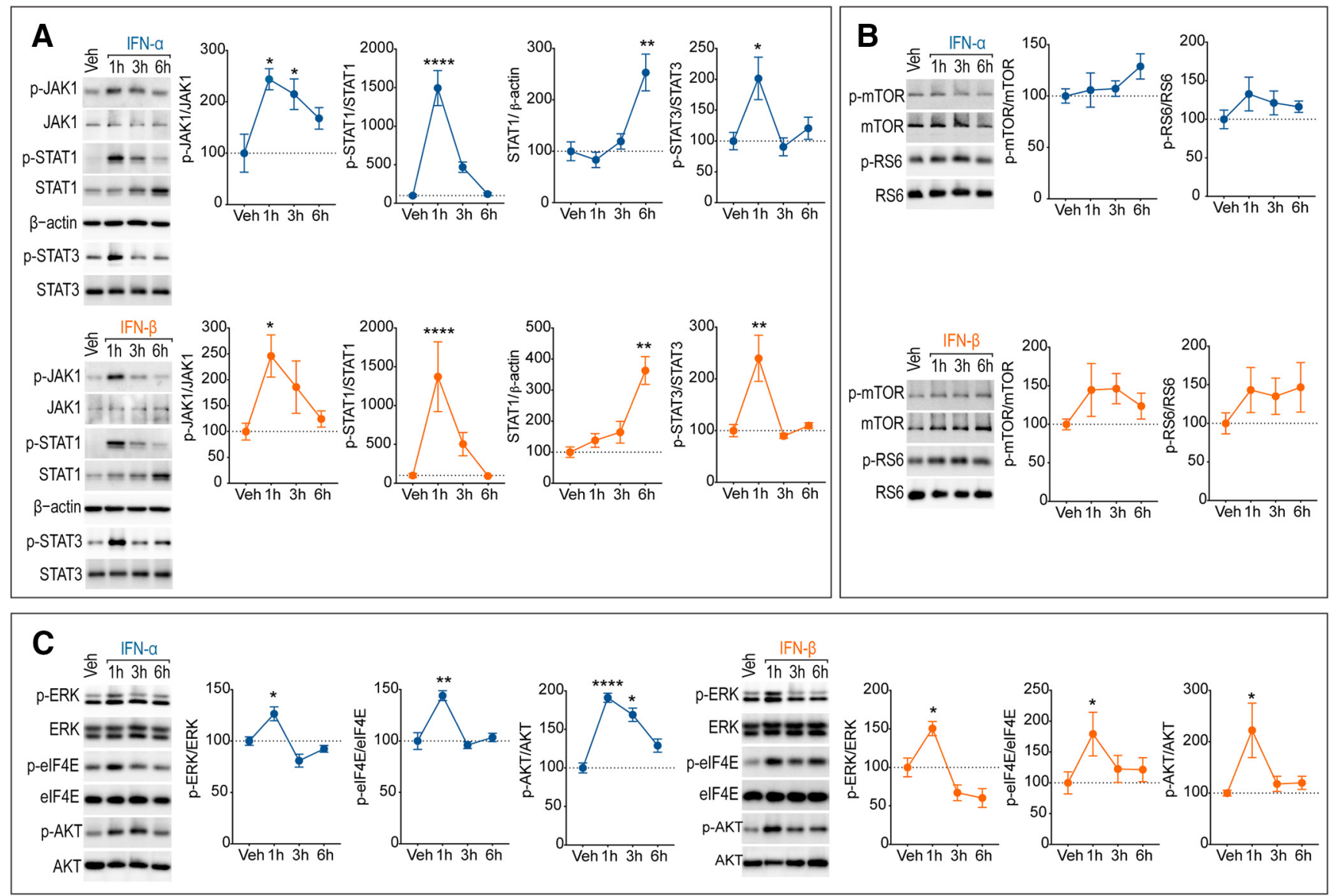

Figure 3. Downstream signaling events associated with IFNRs activation. $A$, Direct stimulation of IFNRs with IFN- $\alpha(300 \mathrm{U} / \mathrm{ml})$ and IFN- $\beta$ (300 U/ml) activated downstream JAK/STAT signaling pathways in cultured DRG neurons. $\boldsymbol{B}$, Neither IFN- $\alpha(300 \mathrm{U} / \mathrm{ml})$ nor IFN- $\beta$ (300 U/ml) induced mTOR or RS6 phosphorylation in DRG cultures over a time course of $6 \mathrm{~h}$. $\boldsymbol{C}$, Time course of the effects produced by IFN- $\alpha(300 \mathrm{U} / \mathrm{ml})$ and IFN- $\beta(300 \mathrm{U} / \mathrm{ml})$ on ERK, elF4E and AKT phosphorylation. Data are presented as mean \pm SEM; $n=3-6$ per group for WB analysis. Group differences (treated vs vehicle) in $\boldsymbol{A}-\boldsymbol{C}$ were assessed using one-way ANOVA followed by Dunnett's multiple-comparisons test. ${ }^{*} p<0.05,{ }^{* *} p<0.01,{ }^{* * *} p<0.0001$.

$\pm 2.9 \mathrm{pF}$ vs IFN- $\alpha 24.3 \pm 1.5 \mathrm{pF}, p=0.89$; diameter: control 26.5 $\pm 0.56 \mathrm{pF}$ vs IFN- $\alpha 26.8 \pm 0.53 \mathrm{pF}, p=0.7$; Fig. $5 A$ ). Resting membrane potential (RMP) was more hyperpolarized than $-40 \mathrm{mV}$ in all cells sampled and IFN- $\alpha$ treatment did not alter the RMP compared with the control group (control $-51.2 \pm$ $3 \mathrm{mV}$ vs IFN- $\alpha-47.5 \pm 2.5 \mathrm{mV}, p=0.38$; Fig. $5 A$ ). In response to ramp current injections mimicking slow depolarizations, DRG neurons exposed to IFN- $\alpha$ showed elevated excitability, measured as the number of action potentials elicited, compared with the control group with a significant main effect of treatment $\left(F_{(1,48)}=22.9, p<0.001\right)$. Significant differences were observed at each time point of ramp injection tested (Fig. 5B,C). We further measured the latency to the first spike following ramp current injection and determined that exposure to IFN- $\alpha$ shortened the latency of initiation of the action potential $\left(F_{(1,48)}=21.02\right.$, $p<0.001$; Fig. $5 D$ ). Therefore, type I IFN exposure rapidly promotes hyperexcitability in small diameter DRG neurons over a time course coinciding with MNK-eIF4E activation.

\section{MNK-eIF4E signaling links type I IFN actions on sensory neurons to mechanical hypersensitivity}

Because we previously observed that ERK/MNK-eIF4E signaling axis was the primary component contributing to IFN- $\alpha$ and IFN- $\beta$ effects in DRG neurons, we targeted this pathway using genetic tools to investigate its contribution to type I IFN-induced pain hypersensitivity. When ERK is activated, it subsequently phosphorylates MNK1/2 (Waskiewicz et al., 1997) leading to phosphorylation of eIF4E at serine 209 (Waskiewicz et al., 1999). We used ICC on cultured DRG neurons to assess whether type 1 IFNs impacts eIF4E phosphorylation at single cell resolution. We found that $1 \mathrm{~h}$ stimulation with either IFN- $\alpha$ (300 U/ml) or IFN- $\beta$ $(300 \mathrm{U} / \mathrm{ml})$ stimulated phosphorylation of eIF4E mostly in neurons expressing peripherin (Fig. 6A,B). Almost all neurons in our cultures were peripherin-positive making it difficult to ascertain whether this effect occurs exclusively in putative nociceptors or also in large diameter low-threshold mechanoreceptive cells. Our expression data suggest that both classes of neurons likely express type I IFNRs (Fig. 2). To assess the behavioral impact of this signaling, we used MNK1-/- mice (Fig. 6C) and tested mechanical hypersensitivity after intraplantar IFN- $\alpha$ (300 U/25 $\mu \mathrm{l})$ or IFN- $\beta$ (300 U/25 $\mu$ l) administration. Mechanical hypersensitivity was attenuated in $\mathrm{MNK} 1-/-$ mice compared with WT mice following IFN application (Fig. 6D,E). Furthermore, mice lacking eIF4E phosphorylation at serine 209 (eIF4E ${ }^{\text {S209A }}$; Fig. $6 F$ ) showed a complete absence of eIF4E phosphorylation in lumbar (L5) DRGs (Fig. 6G) and a significant reduction in mechanical hypersensitivity following intraplantar IFN injection (Fig. 6H,I). We conclude that a MNKeIF4E signaling mechanism strongly contributes to type I IFNinduced pain hypersensitivity.

Induction of endogenous type I interferon response with poly (I:C) causes MNK-eIF4E-dependent pain hypersensitivity Type I IFN responses are caused by viral infections and sustained elevations in type I IFNs have been associated with multiple 

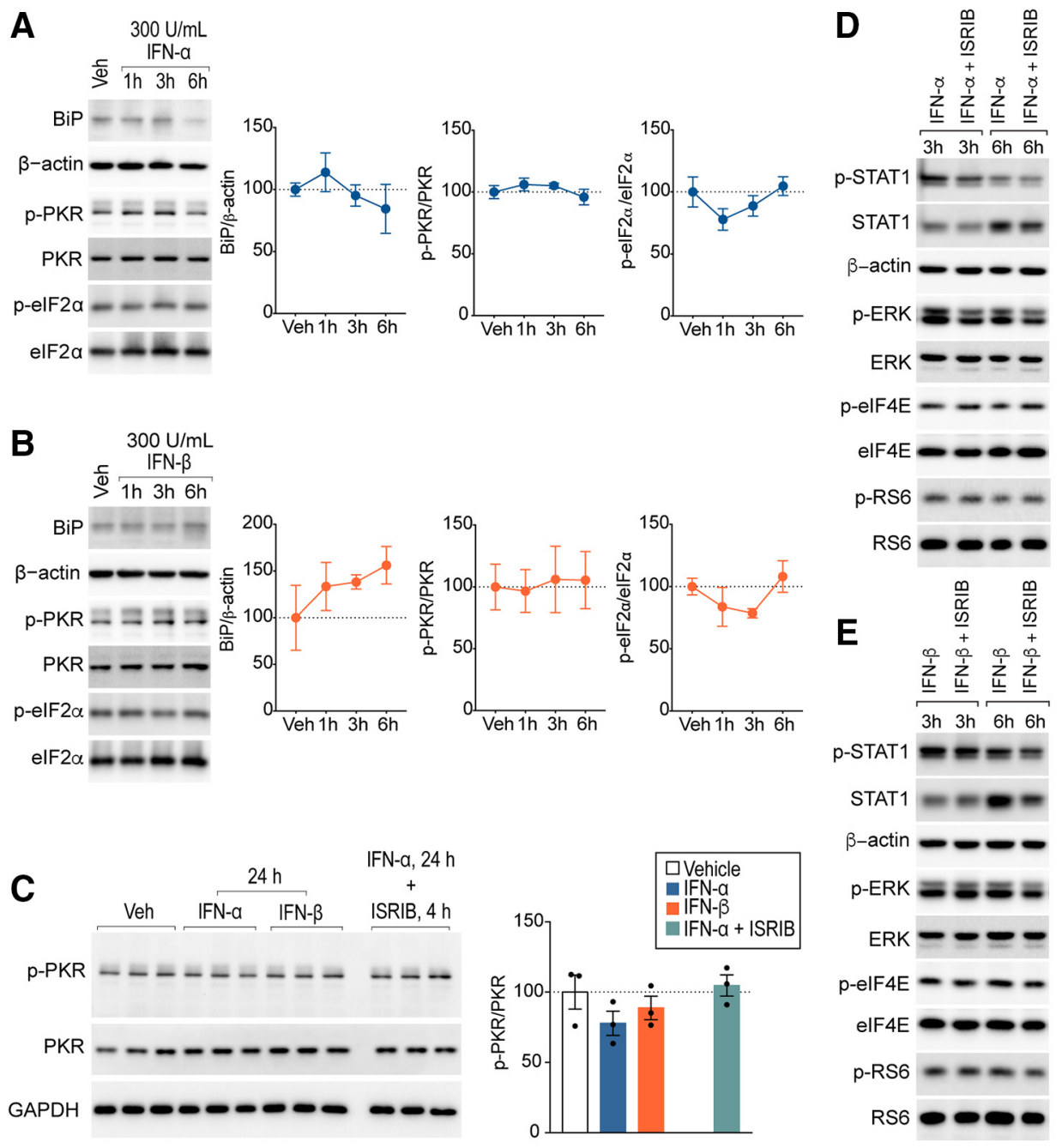
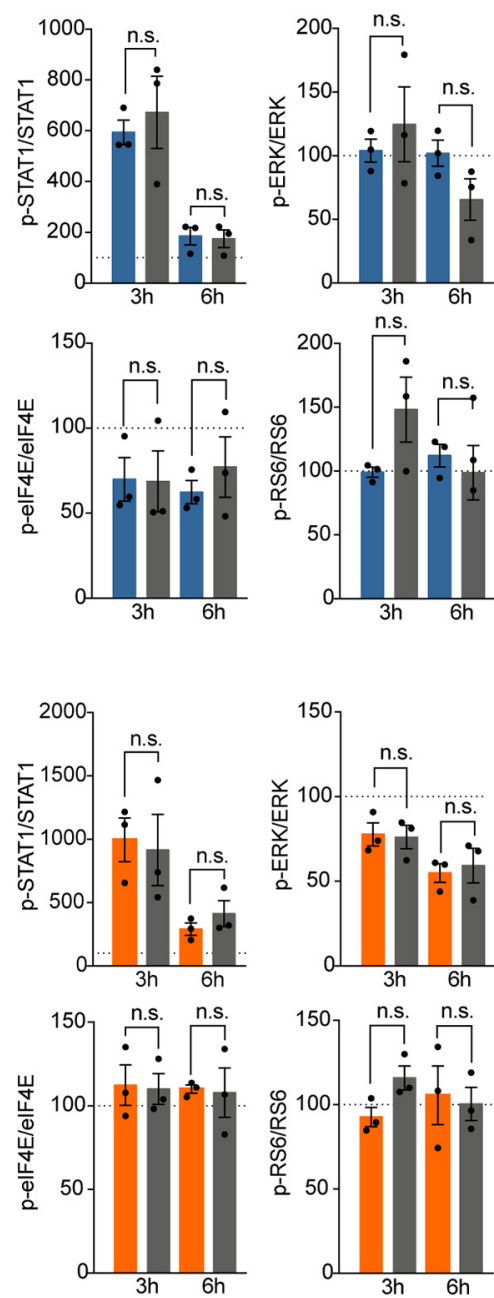

Figure 4. Type I IFNRs activity in cultured DRG neurons is neither associated with BiP-PKR-elF2 $\alpha$ stimulation nor suppressed by the small-molecule ISR inhibitor ISRIB. $\boldsymbol{A}, \boldsymbol{B}$, Application of either IFN- $\alpha(300 \mathrm{U} / \mathrm{ml} ; \boldsymbol{A})$ or IFN- $\beta(300 \mathrm{U} / \mathrm{ml} ; B)$ for $1-6 \mathrm{~h}$ did not modify BiP expression or signaling via PKR and downstream p-elF $\alpha$ in cultured DRG neurons. C, Long exposure (24 h) to IFN- $\alpha(300 \mathrm{U} / \mathrm{ml})$ or IFN- $\beta$ (300 U/ml) did not modify PKR phosphorylation in cultured DRG neurons. Likewise, no changes on PKR phosphorylation after a $24 \mathrm{~h} \mathrm{IFN}-\alpha(300 \mathrm{U} / \mathrm{ml})$ treatment were observed in the presence of the integrated stress response inhibitor ISRIB (200 nM). D, E, The ISR inhibitor ISRIB (200 nM) did not modulate components of the signaling pathways that are activated after either IFN- $\alpha(300 \mathrm{U} / \mathrm{ml} ; \boldsymbol{D})$ or IFN- $\beta(300 \mathrm{U} / \mathrm{ml} ; \boldsymbol{E})$ application. $n=3$ per group. Data are presented as mean \pm SEM. n.S., not significant.

autoimmune diseases including systemic lupus erythematosus and rheumatoid arthritis (Forster, 2012). Moreover, therapeutic IFN- $\alpha$ administration has also been reported as associated with the emergence of somatic symptomatology such as body pain, myalgias, headache, joint pain, abdominal pain (Capuron et al., 2002; Shakoor et al., 2010; Nogueira et al., 2012), and inflammatory hyperalgesia (Fitzgibbon et al., 2019). To investigate how endogenous type I IFN production causes pain sensitization, we intraperitoneally injected mice, for 2 consecutive days, with a synthetic analog of a double-stranded RNA (dsRNA), poly (I:C) $(1 \mathrm{mg} / \mathrm{kg})$. Poly (I:C) is well-known to activate a number of transcription factors, including IFN regulatory factor 3 (IRF3) resulting in the production of IFN- $\alpha$ and IFN- $\beta$ (Kawai and Akira, 2008). We found that mice injected with poly (I:C) developed mechanical hypersensitivity (Fig. 7A) as well as thermal hypersensitivity (Fig. $7 B$ ) over a time course of 3-24 h after the second poly (I:C) administration. Changes in mechanical and thermal hypersensitivity were preceded by an increase in core body temperature, consistent with known physiological effects of poly (I:C) (Fig. 7 C). Based on our previous observations, we hypothesized that the effects seen on thermal and mechanical hypersensitivity would be mechanistically linked to MNK-eIF4E signaling. As predicted, poly (I:C) administration increased phosphorylated eIF4E immunoreactivity in L5 DRGs of WT mice without affecting total eIF4E protein (Fig. 7D). Mechanical (Fig. 7E) and thermal (Fig. $7 F$ ) hypersensitivity produced by poly (I:C) was attenuated in MNK1-/- compared with WT mice. Similarly, mechanical (Fig. $7 G$ ) and thermal $(7 H)$ hypersensitivity was decreased in eIF4E $\mathrm{E}^{\mathrm{S} 209 \mathrm{~A}}$ mice compared with WTs. Moreover, L4-L5 DRGs, lumbar spinal dorsal horn (SDH) and sciatic nerve from MNK1- / - and eIF4 $\mathrm{E}^{\mathrm{S} 209 \mathrm{~A}}$ mice showed a decrease and absence, respectively, of eIF4E phosphorylation compared with WT mice following poly (I:C) administration (Fig. 7I). Finally, we tested whether poly (I:C) had a direct effect on DRG neurons. Direct application of poly (I:C) did not increase p-ERK, p-eIF4E, p-PKR, or p-eIF2 $\alpha$ in cultured DRG neurons (Fig. 7J), suggesting that effects observed with poly (I:C) in vivo are unlikely explained by a direct action of the compound on DRG neurons. Instead, poly (I:C) likely acts via endogenous production of type I IFNs that then act on DRG neurons. These experiments demonstrate that endogenous type I IFN production acts via MNK-eIF4E signaling to induce pain hypersensitivity. 
A
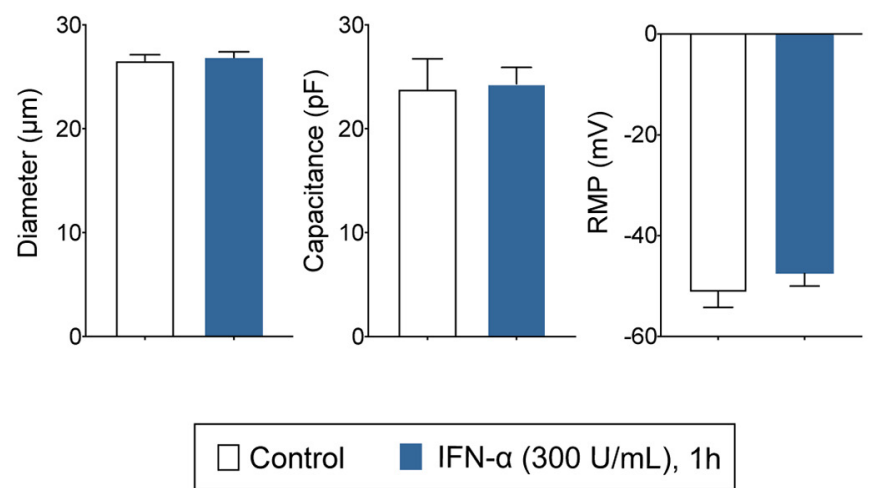

C

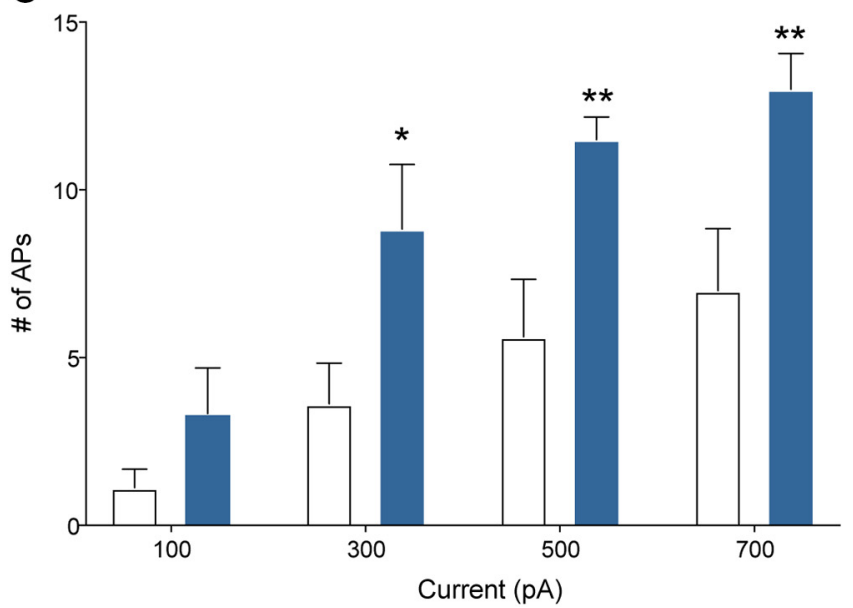

B

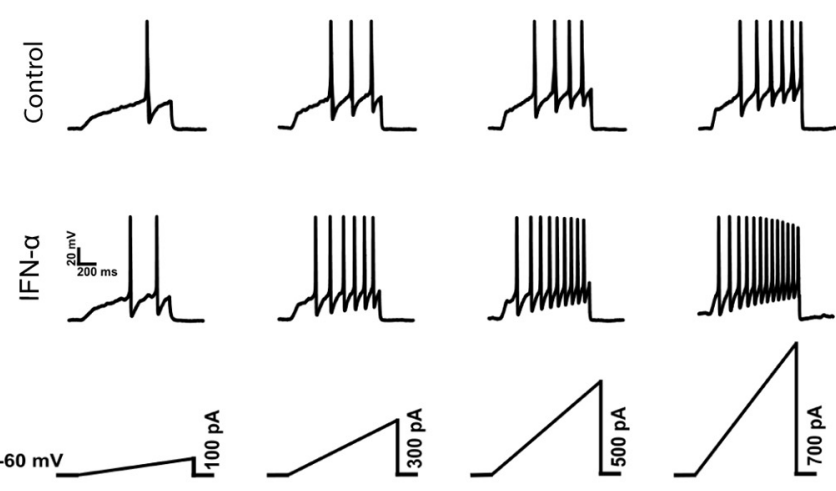

D

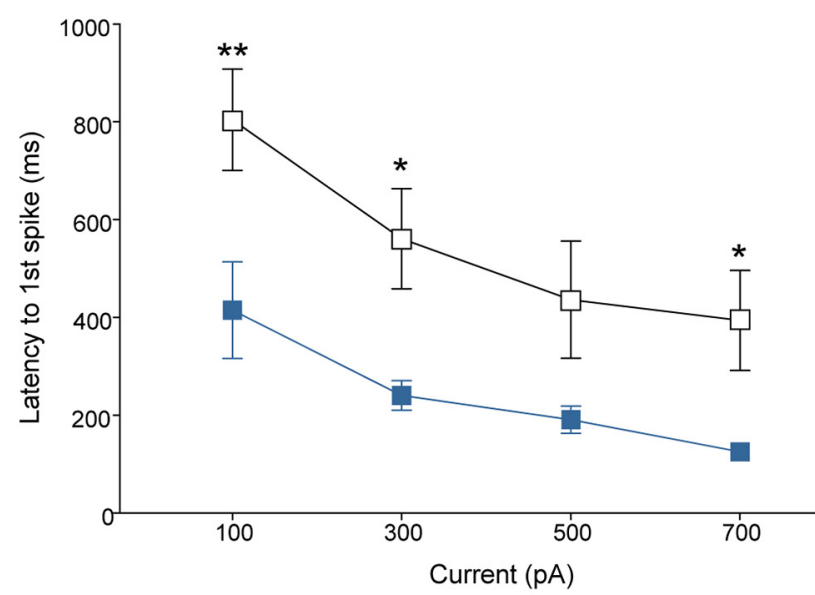

Figure 5. IFN- $\alpha$ treatment causes DRG neuron hyperexcitability. $\boldsymbol{A}$, Small and medium sized DRG neurons were sampled for patch-clamp electrophysiology experiments. The resting membrane potential was similar across the groups, with no significant effect of IFN- $\alpha$ treatment. $\boldsymbol{B}$, Representative traces of action potential firing in the control ( $n=8$ cells) and IFN- $\alpha$ ( $n=6$ cells) groups. Action potentials were elicited by slowly depolarizing ramp currents of varying intensities. $\boldsymbol{C}$, Mean number of action potentials were higher in the IFN- $\alpha$ group at each ramp intensity. D, IFN- $\alpha$ treatment significantly shortened the latency to the first spike. Group differences were assessed using two-way ANOVA followed by Fisher's LSD test. ${ }^{*} p<0.05,{ }^{* *} p<0.01$.

\section{Discussion}

Our findings provide evidence for a mechanistic link between viral infection, type I IFN production, and rapid induction of nociceptor hyperexcitability and mechanical pain sensitization. This occurs via a direct action of type I IFN receptors on sensory neurons and is dependent on downstream signaling via MNKeIF4E. We find no evidence for mTORC1 activation or induction of eIF $2 \alpha$ phosphorylation in DRG neurons by type I IFNs, demonstrating that the key translation regulation pathway engaged is eIF4E phosphorylation. A summary of the main findings from this study are highlighted in a schematic diagram in Figure 8. Collectively, these results provide molecular insight into why one of the first signs of viral infection is body-wide aches and pain.

Although it is well known that viral infection can cause pain, very little work has been done to understand the underlying mechanisms driving this effect (Chiu et al., 2016). Aches and pain caused by viral infection have classically been attributed to fever but these aches and pain often begin before the onset of fever. Our findings with poly (I:C) treatment in mice show that fever and pain effects are disassociated, but in this case the fever clearly preceded hyperalgesia caused by poly (I:C) treatment. An alternative mechanism for viral infection-induced pain is upregulation of IDO1 enzyme and consequent increased production of kynurenine. In support of this idea, mice lacking IDO1 show decreased pain sensitization in response to viral infection
(Huang et al., 2016). However, subsequent work demonstrates that this IDO1 upregulation occurs via virally-mediated upregulation of IFN- $\beta$ and that IDO1 expression can be driven by type I IFNs (Gaelings et al., 2017). Our work demonstrates that this initial type I IFN induction by viral infection can drive a direct sensitization of nociceptors through type I IFN receptors expressed by these sensory neurons. This suggests that early pain sensitization caused by viral infection may proceed independently of IDO1 upregulation. A direct effect of type I IFNs on nociceptors and type I IFN-mediated upregulation of IDO1 and subsequent kynurenine signaling may act in concert to cause prolonged pain responses that can occur with viral infections.

Our work adds to a growing understanding of how pathogens and host-defense responses interact with nociceptors (Chiu et al., 2016). Bacteria can act directly on nociceptors via $N$-formylated peptides that are agonists of G-protein-coupled formyl peptide receptors (Chiu et al., 2013; Pinho-Ribeiro et al., 2017) that are expressed in mouse and human DRG neurons (Ray et al., 2018). Bacteria also release $\alpha$-hemolysin which directly excites nociceptors to cause pain (Chiu et al., 2013; Blake et al., 2018). Although nociceptors can detect bacterial invasion, rapidly sending an alert signal to the brain, they can also play more nuanced roles in bacterial host defense. For instance, gut-innervating nociceptors have very recently been shown to play an active role in defending against Salmonella infection. This happens via an effect of CGRP signaling on intestinal microvilli cells and resident microbiome 
A

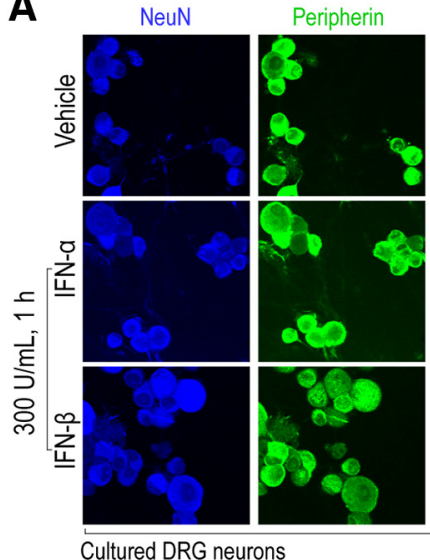

C

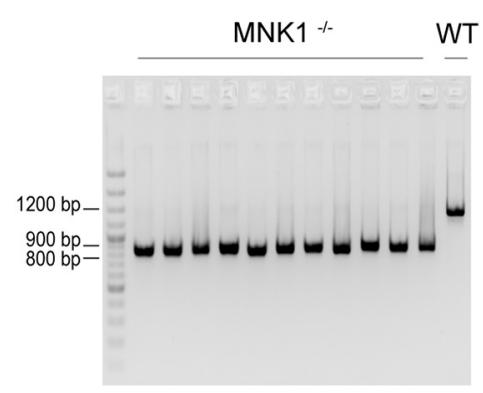

G
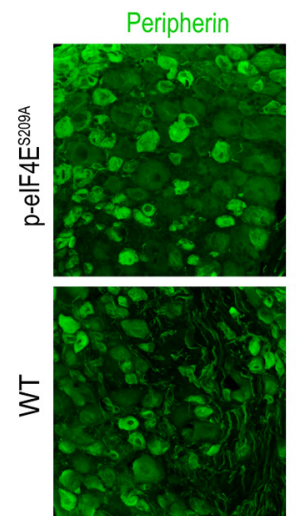

p-elF4E ${ }^{\text {S209 }}$

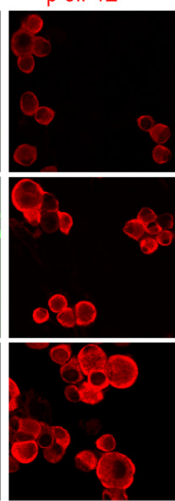

D

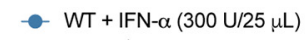
-1- MNK1 $1^{-1-}+$ IFN- $\alpha(300 \mathrm{U} / 25 \mu \mathrm{L})$

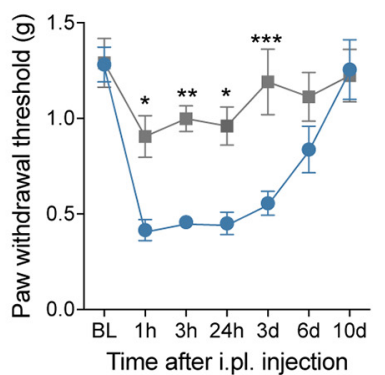

Time after i.pl. injection

Merge
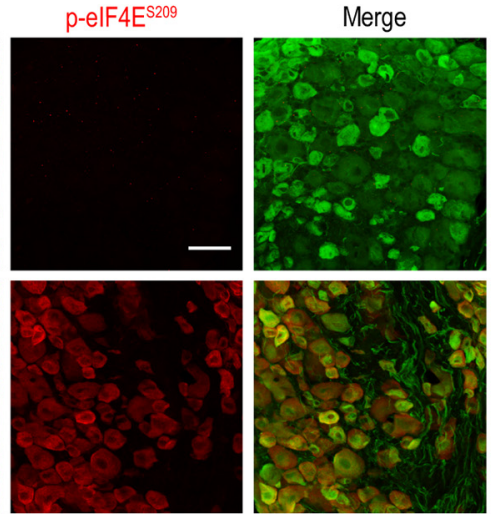
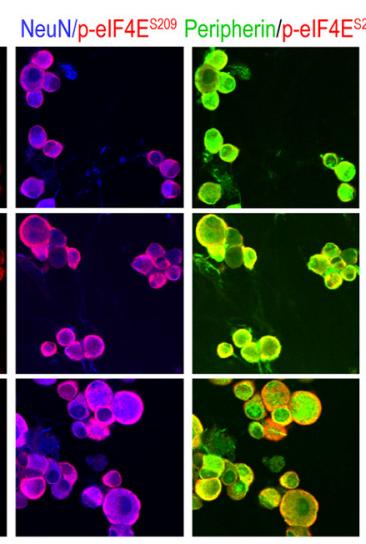

E

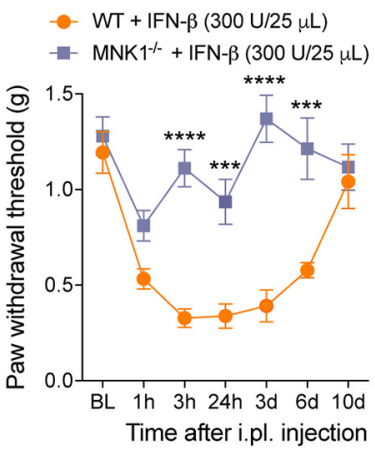

H

- $W T+$ IFN- $\alpha(300 \mathrm{U} / 25 \mu \mathrm{L})$

$-\mathrm{elF} 4 \mathrm{E}^{\mathrm{S} 209 \mathrm{~A}}+\mathrm{IFN}-\alpha(300 \mathrm{U} / 25 \mu \mathrm{L})$

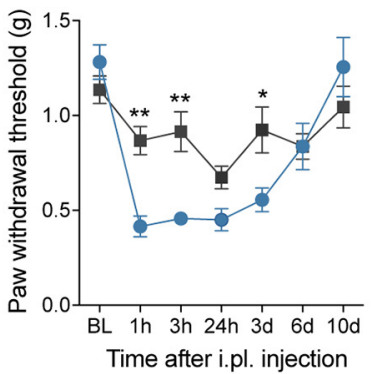

B

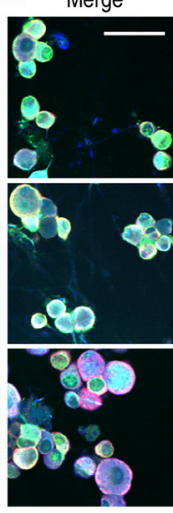

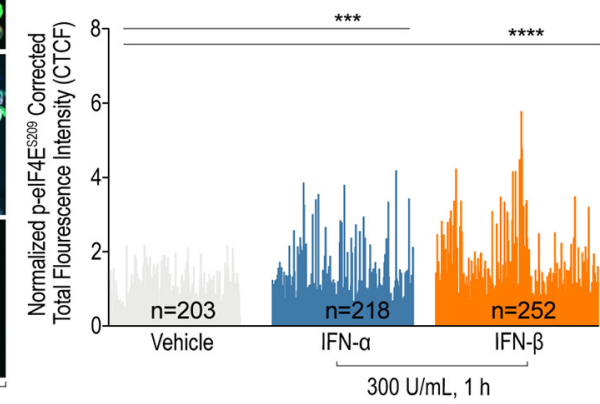

F

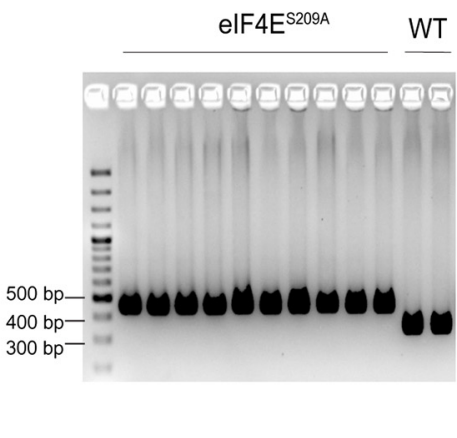

I

- WT + IFN- $\beta(300 \mathrm{U} / 25 \mu \mathrm{L})$

- elF4ES209A + IFN- $\beta(300 \mathrm{U} / 25 \mu \mathrm{L})$

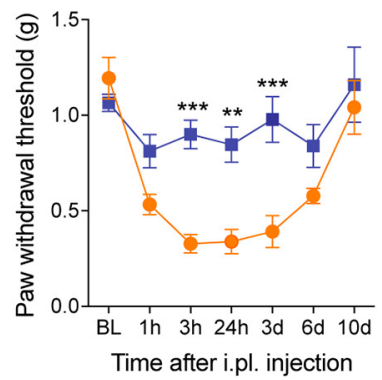

Figure 6. Genetic and pharmacological targeting of the MNK-elF4E signaling axis attenuates type I IFN-induced pain hypersensitivity. A, B, One hour stimulation with either IFN- $\alpha$ (300 U/ $\mathrm{ml})$ or IFN- $\beta(300 \mathrm{U} / \mathrm{ml})$ increased the phosphorylation of the translation initiation factor elF4E at serine $\mathrm{S} 209$ (elF4E ${ }^{5209}$; red) in cultured DRG neurons expressing NeuN (blue) and peripherin (green). Scale bar, $50 \mu \mathrm{m}$. Data are presented as mean \pm SEM. Group differences were assessed using one-way ANOVA followed by Dunnett's multiple-comparisons test. C, MNK1-I- mouse genotyping. $\boldsymbol{D}, \boldsymbol{E}$, Mechanical hypersensitivity produced by intraplantar (i.pl.) administration of either IFN- $\alpha$ (300 U/25 $\mu \mathrm{l} ; \boldsymbol{D})$ or IFN- $\beta$ (300 U/25 $\mu$ l; $\boldsymbol{E})$ was attenuated in mice lacking MNK1 $(M k n k 1-/-)$, the specific kinase that phosphorylates elF4E. Data are presented as mean \pm SEM; $n=6$ per group. Group differences were assessed using two-way ANOVA followed by Bonferroni's multiple-comparisons test. ${ }^{*} p<0.05,{ }^{* *} p<0.01,{ }^{* * *} p<0.001,{ }^{* * *} p<0.0001$. $\boldsymbol{F}$, elF4E ${ }^{5209 A}$ mouse genotyping. $\boldsymbol{G}$, Mice lacking the phosphorylation site at Serine 209

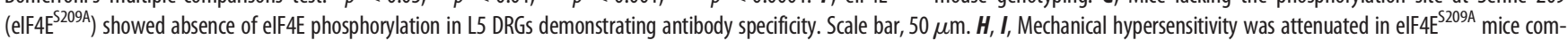
pared with WT mice following an intraplantar injection of either IFN- $\alpha(300 \mathrm{U} / 25 \mu \mathrm{l} ; \boldsymbol{H})$ or IFN- $\beta$ (300 U/25 $\mu$ l; $\boldsymbol{l}$ ). Data are presented as mean \pm SEM; $n=6$ per group. Group differences were assessed using two-way ANOVA followed by Bonferroni's multiple-comparisons test. ${ }^{*} p<0.05,{ }^{* *} p<0.01,{ }^{* * *} p<0.001$.

to protect against Salmonella invasiveness (Lai et al., 2020). In the case of viruses, we find that a dsRNA mimetic, poly (I:C), does not seem to have a direct effect on nociceptors, suggesting that immune and other somatic cells are likely the first detectors of viral infection. Our findings clearly demonstrate, however, that one of the earliest responses to viral infection, production of type I IFN, causes robust and rapid sensitization of nociceptors via a specific translation regulation signaling cascade. Our findings regarding the action of type I IFNs on nociceptors are opposed to the recent work of Liu et al. (2016) who found that
IFN $\alpha$ causes inhibition of pain signaling at the level of the dorsal horn. These authors proposed that type I IFNs from astrocytes cause presynaptic inhibition of neurotransmitter release from nociceptors therefore reducing pain signaling. It is possible that CNS-released type I IFNs have a different action on nociceptor central terminals than type I IFNs released in the periphery have on nociceptor peripheral ending and cell bodies. Another possibility is that very high doses of type I IFNs (5000-10,000 U) produce an inhibition of MAPK signaling, as recently shown in the dorsal horn in the context of neuropathic pain (Liu et al., 2019). 
A

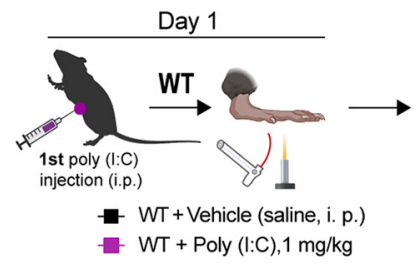

B
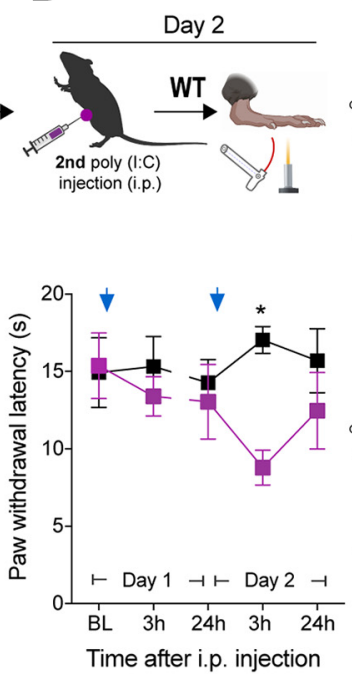

$\mathbf{F}$

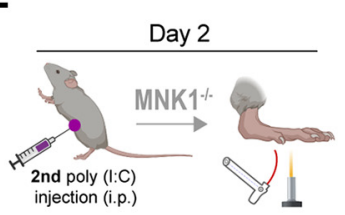

C

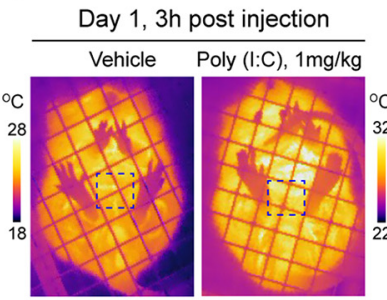

Day 2, 3h post injection

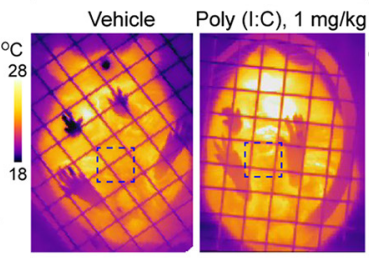

G

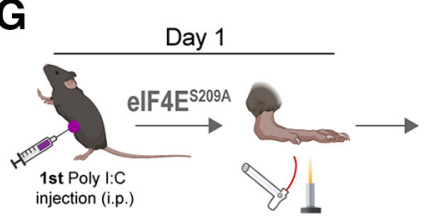

늘 $W T+$ poly (l:C), $1 \mathrm{mg} / \mathrm{kg}$

- elF4E $\mathrm{E}^{2200 \mathrm{~A}}+$ poly $(\mathrm{l}: \mathrm{C}), 1 \mathrm{mg} / \mathrm{kg}$
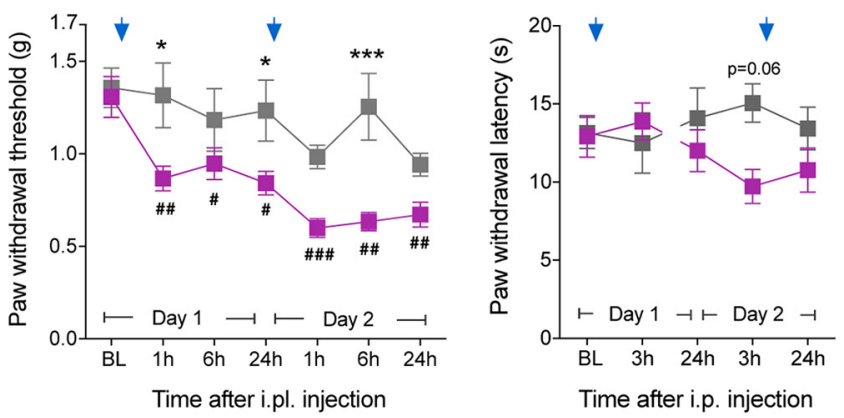

D

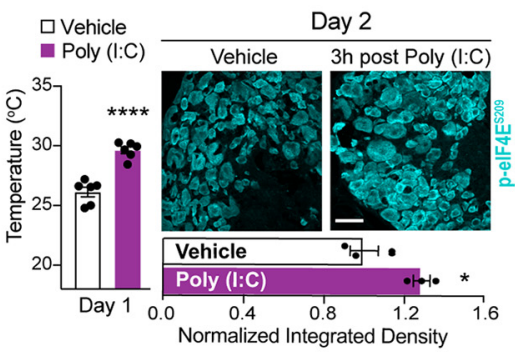

Vehicle $\quad 3 h$ post Poly (I:C)

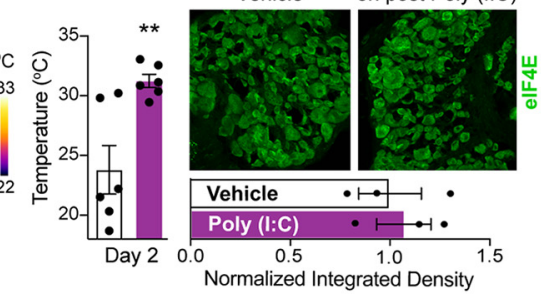

H

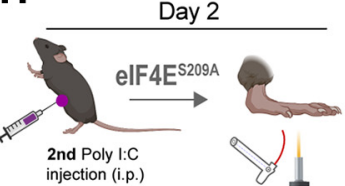

I

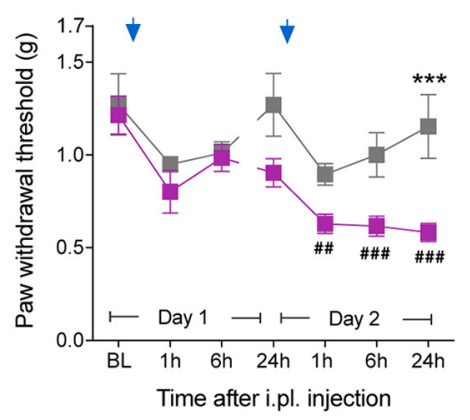

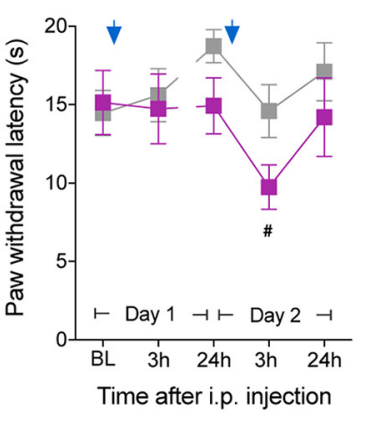

J

Cultured DRG neurons

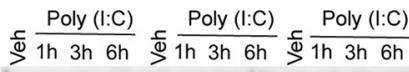

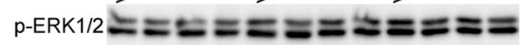

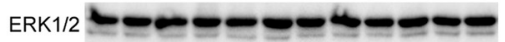
p-elF4E - - - - - - elF4E - - - - - -

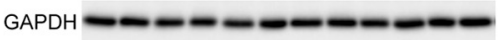

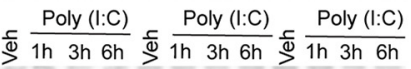
p-PKR - - - - - - - - -

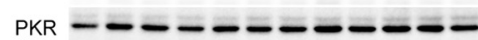
p-elF2a $\cdots+-\cdots--1-\cdots$ elF2a

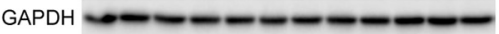

$5 \sum \frac{\bar{s}}{5}$
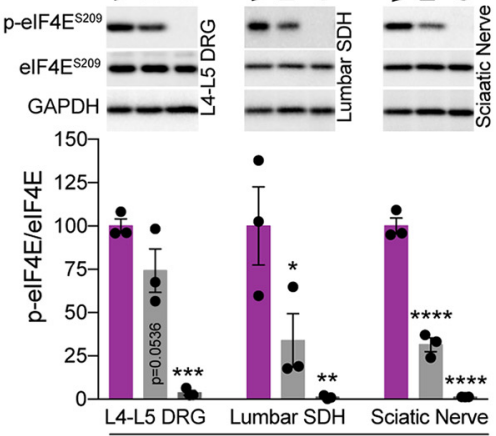

Poly (l:C), $1 \mathrm{mg} / \mathrm{kg}$, Day 2

Figure 7. Endogenous type I IFN induction with poly (l:C) produces pain sensitization in mice via MNK1-elF4E signaling. $\boldsymbol{A}, \boldsymbol{B}$, The synthetic analog of a double-stranded RNA (dsRNA), poly (l:C) $\left(1 \mathrm{mg} / \mathrm{kg}\right.$, i.p.), injected for 2 consecutive days, produced mechanical $(\boldsymbol{A})$ and thermal hypersensitivity $(\boldsymbol{B})$ in mice. $n=6$ per group. ${ }^{*} p<0.05,{ }^{* *} p<0.01$, compare to vehicle. ${ }_{p}^{\#}<0.05,{ }^{\# \#}<0.01,{ }^{\# \#} p<0.001,{ }^{\# \# \#} p<0.0001$ compare to baseline. Group differences were assessed using two-way ANOVA followed by Dunnett's (\#) or Bonferroni's (*) multiple-comparisons tests. $C$, Changes in body temperature produced by intraperitoneal poly $(\mathrm{l}: \mathrm{C})(1 \mathrm{mg} / \mathrm{kg})$ administration. $n=6$ per group. ${ }^{* *} p<0.01,{ }^{* * * *} p<0.0001$ compared with vehicle. Group differences were assessed using unpaired $t$ test. $\boldsymbol{D}$, Intraperitoneal poly (l:C) administration increased phospho, but not total, elF4E in L5 DRGs of WT mice at Day 2 (3 h post-second poly I:C injection). Scale bar, $50 \mu \mathrm{m} . n=3$ per group. ${ }^{*} p<0.05$ compared with vehicle. Group differences were assessed using unpaired $t$ test. Mechanical $(\boldsymbol{E})$ and thermal $(\boldsymbol{F})$ hypersensitivity 
We show that lower doses of type I IFNs (300 $\mathrm{U})$ produce clear MAPK signaling activation in DRG neurons in vitro and in vivo. The dose used in our experiments is consistent with earlier studies examining dose-dependent effects of type I IFN signaling on what are now known as canonical signaling pathways (Larner et al., 1986; Hilkens et al., 2003) and with plasma levels induced by virus (Gerlach et al., 2006; Murray et al., 2015; Cheng et al., 2017) or poly (I:C) (Shibamiya et al., 2009).

Translation regulation is a central mechanism driving nociceptor hyperexcitability and mechanical pain (Khoutorsky and Price, 2018). A key antiviral response is activation of PKR and downstream phosphorylation of eIF2 $\alpha$ (Balachandran and Barber, 2007). This results in decreased cap-dependent translation and suppression of viral replication capability in host cells. Another upstream eIF2 $\alpha$ kinase, PERK, is activated in DRG neurons in diabetic neuropathy (Inceoglu et al., 2015), an effect that is likely mediated by the toxic end glycation byproduct methylglyoxal (Barragan-Iglesias et al., 2019). We initially hypothesized that type I IFNs might induce eIF2 $\alpha$ phosphorylation in DRG neurons via PKR activation given the well established induction of this pathway in other cell types (Pindel and Sadler, 2011). We did not find evidence for type I IFN-induced PKR-eIF2 $\alpha$ signaling in DRG neurons, even over long time courses. Instead, we observed clear evidence for rapid activation of MNK1-eIF4E signaling in DRG neurons in vitro and in vivo. Signaling via eIF4E was also critical for the production of mechanical pain responses by type I IFNs and poly (I:C), which produces endogenous type I IFN production (Yamamoto et al., 2003; Kawai and Akira, 2008). Activation of MNK-eIF4E signaling by type I IFNs has been observed in other cell types where it has been linked to increased immune surveillance (Joshi et al., 2009). Multiple previous studies have

produced by intraplantar administration of poly (I:C) $(1 \mathrm{mg} / \mathrm{kg})$ were partially attenuated in MNK1 $1-1-$ mice compared with WT mice. ${ }^{* *} p<0.001$, compare to WT

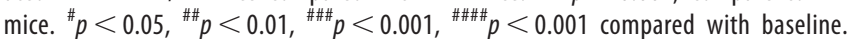
$n=12$ (WT) and $n=6$ (MNK1-/-) per group. Group differences were assessed using two-way ANOVA followed by Dunnett's (\#) or Bonferroni's $\left({ }^{*}\right)$ multiple-comparisons tests. Mechanical $(\boldsymbol{G})$ and thermal $(\boldsymbol{H})$ hypersensitivity produced by intraplantar administration of poly (I:C) $(1 \mathrm{mg} / \mathrm{kg})$ were attenuated in elF4E $\mathrm{E}^{\mathrm{S209A}}$ mice compared with WT mice. $n=12$ (WT) and $n=6$ (elF4E ${ }^{5209 A}$ ) per group. ${ }^{*} p<0.05$, ${ }^{* * *} p<0.001$ compared with WT mice, ${ }^{*} p<0.05,{ }^{\# \#} p<0.01$, ${ }^{\# \#} p<0.001$ compared with baseline. Group differences were assessed using two-way ANOVA followed by Dunnett's (\#) or Bonferroni's (*) multiple-comparisons tests. I, Lumbar DRGS (L4L5), lumbar SDH and sciatic nerve from MNK- - - and elF45 $\mathrm{E}^{\mathrm{S} 209 \mathrm{~A}}$ mice showed decrease and absence, respectively, on elF4E phosphorylation compared with WT mice following intraperitoneal poly $\mathrm{I}: \mathrm{C}$ administration (Day 2, $3 \mathrm{~h}$ post-second poly (I:C) injection). $n=3$ per group. ${ }^{*} p<0.05,{ }^{* *} p<0.01,{ }^{* * *} p<0.001,{ }^{* * * *} p<0.001$ compared with WT. Differences were assessed using one-way ANOVA followed by Dunnett's multiple-comparisons test. J, Application of poly (I:C) $(10 \mu \mathrm{g} / \mathrm{ml})$ did not increase $\mathrm{p}$-ERK, $\mathrm{p}$-elF4E, $\mathrm{p}$-PKR or $\mathrm{p}$-elF2 $\alpha$ in cultured DRG neurons. $n=3$ per group. demonstrated that activation of MNK-eIF4E-mediated translation events are causative in the production of chronic pain states, including neuropathic pain (Moy et al., 2017; Megat et al., 2019; Shiers et al., 2020). Because both viral infections and prolonged production of type I IFNs can cause neuropathic pain, it is possible that type I IFN receptor signaling to MNK-eIF4E may be a key pathway for production of these types of neuropathies.

\section{References}

Aziz-Donnelly A, Harrison TB (2017) Update of HIV-associated sensory neuropathies. Curr Treat Options Neurol 19:36.

Balachandran S, Barber GN (2007) PKR in innate immunity, cancer, and viral oncolysis. Methods Mol Biol 383:277-301.

Baral P, Mills K, Pinho-Ribeiro FA, Chiu IM (2016) Pain and itch: beneficial or harmful to antimicrobial defense? Cell Host Microbe 19:755-759.

Barragan-Iglesias P, Kuhn J, Vidal-Cantu GC, Salinas-Abarca AB, GranadosSoto V, Dussor GO, Campbell ZT, Price TJ (2019) Activation of the integrated stress response in nociceptors drives methylglyoxal-induced pain. Pain 160:160-171.

Barrat FJ, Crow MK, Ivashkiv LB (2019) Interferon target-gene expression and epigenomic signatures in health and disease. Nat Immunol 20:1574-1583.

Blake KJ, Baral P, Voisin T, Lubkin A, Pinho-Ribeiro FA, Adams KL, Roberson DP, Ma YC, Otto M, Woolf CJ, Torres VJ, Chiu IM (2018) Staphylococcus aureus produces pain through pore-forming toxins and neuronal TRPV1 that is silenced by QX-314. Nat Commun 9:37. 
Brizzi KT, Lyons JL (2014) Peripheral nervous system manifestations of infectious diseases. Neurohospitalist 4:230-240.

Butler A, Hoffman P, Smibert P, Papalexi E, Satija R (2018) Integrating single-cell transcriptomic data across different conditions, technologies, and species. Nat Biotechnol 36:411-420.

Capuron L, Gumnick JF, Musselman DL, Lawson DH, Reemsnyder A, Nemeroff CB, Miller AH (2002) Neurobehavioral effects of interferon- $\alpha$ in cancer patients: phenomenology and paroxetine responsiveness of symptom dimensions. Neuropsychopharmacology 26:643-652.

Chaplan SR, Bach FW, Pogrel JW, Chung JM, Yaksh TL (1994) Quantitative assessment of tactile allodynia in the rat paw. J Neurosci Methods 53:5563.

Cheng L, Yu H, Li G, Li F, Ma J, Li J, Chi L, Zhang L, Su L (2017) Type I interferons suppress viral replication but contribute to $\mathrm{T}$ cell depletion and dysfunction during chronic HIV-1 infection. JCI Insight 2:94366.

Chiu IM, Pinho-Ribeiro FA, Woolf CJ (2016) Pain and infection: pathogen detection by nociceptors. Pain 157:1192-1193.

Chiu IM, Heesters BA, Ghasemlou N, Von Hehn CA, Zhao F, Tran J, Wainger B, Strominger A, Muralidharan S, Horswill AR, Bubeck Wardenburg J, Hwang SW, Carroll MC, Woolf CJ (2013) Bacteria activate sensory neurons that modulate pain and inflammation. Nature 501:52-57.

de la Pena JBI, Song JJ, Campbell ZT (2019) RNA control in pain: blame it on the messenger. Wiley Interdiscip Rev RNA 10:e1546.

de Weerd NA, Nguyen T (2012) The interferons and their receptors-distribution and regulation. Immunol Cell Biol 90:483-491.

Fitzgibbon M, Kerr DM, Henry RJ, Finn DP, Roche M (2019) Endocannabinoid modulation of inflammatory hyperalgesia in the IFN- $\alpha$ mouse model of depression. Brain Behav Immun 82:372-381.

Forster S (2012) Interferon signatures in immune disorders and disease. Immunol Cell Biol 90:520-527.

Foster SL, Seehus CR, Woolf CJ, Talbot S (2017) Sense and immunity: context-dependent neuro-immune interplay. Front Immunol 8:1463.

Furic L, Rong L, Larsson O, Koumakpayi IH, Yoshida K, Brueschke A, Petroulakis E, Robichaud N, Pollak M, Gaboury LA, Pandolfi PP, Saad F, Sonenberg N (2010) eIF4E phosphorylation promotes tumorigenesis and is associated with prostate cancer progression. Proc Natl Acad Sci U S A 107:14134-14139.

Gaelings L, Söderholm S, Bugai A, Fu Y, Nandania J, Schepens B, Lorey MB, Tynell J, Vande Ginste L, Le Goffic R, Miller MS, Kuisma M, Marjomäki V, De Brabander J, Matikainen S, Nyman TA, Bamford DH, Saelens X, Julkunen I, Paavilainen H, et al. (2017) Regulation of kynurenine biosynthesis during influenza virus infection. FEBS J 284:222-236.

Gerlach N, Schimmer S, Weiss S, Kalinke U, Dittmer U (2006) Effects of type I interferons on Friend retrovirus infection. J Virol 80:3438-3444.

Hadley GR, Gayle JA, Ripoll J, Jones MR, Argoff CE, Kaye RJ, Kaye AD (2016) Post-herpetic neuralgia: a review. Curr Pain Headache Rep 20:17.

Hargreaves K, Dubner R, Brown F, Flores C, Joris J (1988) A new and sensitive method for measuring thermal nociception in cutaneous hyperalgesia. Pain 32:77-88.

Hilkens CM, Schlaak JF, Kerr IM (2003) Differential responses to IFN- $\alpha$ subtypes in human T cells and dendritic cells. J Immunol 171:5255-5263.

Hjortsberg L, Lindvall C, Corcoran M, Arulampalam V, Chan D, Thyrell L, Nordenskjold M, Grander D, Pokrovskaja K (2007) Phosphoinositide 3kinase regulates a subset of interferon-alpha-stimulated genes. Exp Cell Res 313:404-414.

Huang L, Ou R, Rabelo de Souza G, Cunha TM, Lemos H, Mohamed E, Li L, Pacholczyk G, Randall J, Munn DH, Mellor AL (2016) Virus infections incite pain hypersensitivity by inducing indoleamine 2,3 dioxygenase. PLoS Pathog 12:e1005615.

Inceoglu B, Bettaieb A, Trindade da Silva CA, Lee KS, Haj FG, Hammock BD (2015) Endoplasmic reticulum stress in the peripheral nervous system is a significant driver of neuropathic pain. Proc Natl Acad Sci USA 112:9082-9087.

Ivashkiv LB, Donlin LT (2014) Regulation of type I interferon responses. Nat Rev Immunol 14:36-49.

Joshi S, Kaur S, Redig AJ, Goldsborough K, David K, Ueda T, WatanabeFukunaga R, Baker DP, Fish EN, Fukunaga R, Platanias LC (2009) Type I interferon (IFN)-dependent activation of Mnk1 and its role in the generation of growth inhibitory responses. Proc Natl Acad Sci U S A 106:12097-12102.
Kawai T, Akira S (2008) Toll-like receptor and RIG-I-like receptor signaling. Ann N Y Acad Sci 1143:1-20.

Khoutorsky A, Price TJ (2018) Translational control mechanisms in persistent pain. Trends Neurosci 41:100-114.

Khoutorsky A, Sorge RE, Prager-Khoutorsky M, Pawlowski SA, Longo G, Jafarnejad SM, Tahmasebi S, Martin LJ, Pitcher MH, Gkogkas CG, Sharif-Naeini R, Ribeiro-da-Silva A, Bourque CW, Cervero F, Mogil JS, Sonenberg N (2016) eIF2alpha phosphorylation controls thermal nociception. Proc Natl Acad Sci USA 113:11949-11954.

Lai NY, Musser MA, Pinho-Ribeiro FA, Baral P, Jacobson A, Ma P, Potts DE, Chen Z, Paik D, Soualhi S, Yan Y, Misra A, Goldstein K, Lagomarsino VN, Nordstrom A, Sivanathan KN, Wallrapp A, Kuchroo VK, Nowarski R, Starnbach MN, et al. (2020) Gut-innervating nociceptor neurons regulate Peyer's patch microfold cells and SFB levels to mediate salmonella host defense. Cell 180:33-49.e22.

Larner AC, Chaudhuri A, Darnell JE Jr (1986) Transcriptional induction by interferon. New protein(s) determine the extent and length of the induction. J Biol Chem 261:453-459.

Levy DE, Darnell JE Jr (2002) Stats: transcriptional control and biological impact. Nat Rev Mol Cell Biol 3:651-662.

Li CL, Li KC, Wu D, Chen Y, Luo H, Zhao JR, Wang SS, Sun MM, Lu YJ, Zhong YQ, Hu XY, Hou R, Zhou BB, Bao L, Xiao HS, Zhang X (2016) Somatosensory neuron types identified by high-coverage single-cell RNA-sequencing and functional heterogeneity. Cell Res 26:83-102.

Liu CC, Gao YJ, Luo H, Berta T, Xu ZZ, Ji RR, Tan PH (2016) Interferon alpha inhibits spinal cord synaptic and nociceptive transmission via neuronal-glial interactions. Sci Rep 6:34356.

Liu S, Karaganis S, Mo RF, Li XX, Wen RX, Song XJ (2019) IFN $\beta$ treatment inhibits nerve injury-induced mechanical allodynia and MAPK signaling by activating ISG15 in mouse spinal cord. J Pain. Advance online publication. Retrieved November 27, 2019. doi: 10.1016/j.jpain.2019.11.010.

Liu T, Gao YJ, Ji RR (2012) Emerging role of Toll-like receptors in the control of pain and itch. Neurosci Bull 28:131-144.

Malcangio M (2019) Role of the immune system in neuropathic pain. Scan J Pain 20:33-37.

Megat S, Ray PR, Moy JK, Lou TF, Barragan-Iglesias P, Li Y, Pradhan G, Wanghzou A, Ahmad A, Burton MD, North RY, Dougherty PM, Khoutorsky A, Sonenberg N, Webster KR, Dussor G, Campbell ZT, Price TJ (2019) Nociceptor translational profiling reveals the Ragulator-Rag GTPase complex as a critical generator of neuropathic pain. J Neurosci 39:393-411.

Moy JK, Khoutorsky A, Asiedu MN, Black BJ, Kuhn JL, Barragan-Iglesias P, Megat S, Burton MD, Burgos-Vega CC, Melemedjian OK, Boitano S, Vagner J, Gkogkas CG, Pancrazio JJ, Mogil JS, Dussor G, Sonenberg N, Price TJ (2017) The MNK-eIF4E signaling axis contributes to injuryinduced nociceptive plasticity and the development of chronic pain. J Neurosci 37:7481-7499.

Munir M, Berg M (2013) The multiple faces of proteinkinase R in antiviral defense. Virulence 4:85-89.

Murray C, Griffin EW, O'Loughlin E, Lyons A, Sherwin E, Ahmed S, Stevenson NJ, Harkin A, Cunningham C (2015) Interdependent and independent roles of type I interferons and IL-6 in innate immune, neuroinflammatory and sickness behaviour responses to systemic poly I:C. Brain Behav Immun 48:274-286.

Nogueira JBC, Sena LCS, Quintans J. d S S, Almeida J. R G d S, França AVC, Júnior LJQ (2012) Side effects of the therapy with peginterferon and ribavirin in chronic hepatitis C: a small audit. J Pharm Pract 25:85-88.

Obara I, Hunt SP (2014) Axonal protein synthesis and the regulation of primary afferent function. Dev Neurobiol 74:269-278.

Pindel A, Sadler A (2011) The role of protein kinase R in the interferon response. J Interferon Cytokine Res 31:59-70.

Pinho-Ribeiro FA, Verri WA Jr, Chiu IM (2017) Nociceptor sensory neuronimmune interactions in pain and inflammation. Trends Immunol 38:519.

Platanias LC (2005) Mechanisms of type-I- and type-II-interferon-mediated signalling. Nat Rev Immunol 5:375-386.

Ray P, Torck A, Quigley L, Wangzhou A, Neiman M, Rao C, Lam T, Kim JY, Kim TH, Zhang MQ, Dussor G, Price TJ (2018) Comparative transcriptome profiling of the human and mouse dorsal root ganglia: an RNAseq-based resource for pain and sensory neuroscience research. Pain 159:1325-1345. 
Rodríguez Y, Vatti N, Ramírez-Santana C, Chang C, Mancera-Páez O, Gershwin ME, Anaya JM (2019) Chronic inflammatory demyelinating polyneuropathy as an autoimmune disease. J Autoimmun 102:8-37.

Saleiro D, Mehrotra S, Kroczynska B, Beauchamp EM, Lisowski P, Majchrzak-Kita B, Bhagat TD, Stein BL, McMahon B, Altman JK, Kosciuczuk EM, Baker DP, Jie C, Jafari N, Thompson CB, Levine RL, Fish EN, Verma AK, Platanias LC (2015) Central role of ULK1 in type I interferon signaling. Cell Rep 11:605-617.

Schreiber G (2017) The molecular basis for differential type I interferon signaling. J Biol Chem 292:7285-7294.

Sen GC, Sarkar SN (2007) The interferon-stimulated genes: targets of direct signaling by interferons, double-stranded RNA, and viruses. Curr Top Microbiol Immunol 316:233-250.

Shakoor A, Shafqat F, Mehmud T, Akram M, Riaz S, Iqbal Z, Khan AA (2010) Frequency of depression and somatic symptoms in patients on interferon alpha/ribavirin for chronic hepatitis C. J Ayub Med Coll Abbottabad 22:6-9.

Shibamiya A, Hersemeyer K, Schmidt Woll T, Sedding D, Daniel JM, Bauer S, Koyama T, Preissner KT, Kanse SM (2009) A key role for Toll-like receptor-3 in disrupting the hemostasis balance on endothelial cells. Blood 113:714-722.

Shiers S, Mwirigi J, Pradhan G, Kume M, Black B, Barragan-Iglesias P, Moy JK, Dussor G, Pancrazio JJ, Kroener S, Price TJ (2020) Reversal of peripheral nerve injury-induced neuropathic pain and cognitive dysfunction via genetic and tomivosertib targeting of MNK. Neuropsychopharmacol 45:524-533.
Stark GR, Darnell JE Jr (2012) The JAK-STAT pathway at twenty. Immunity 36:503-514.

Thyrell L, Hjortsberg L, Arulampalam V, Panaretakis T, Uhles S, Dagnell M, Zhivotovsky B, Leibiger I, Grander D, Pokrovskaja K (2004) Interferon $\alpha$-induced apoptosis in tumor cells is mediated through the phosphoinositide 3-kinase/mammalian target of rapamycin signaling pathway. J Biol Chem 279:24152-24162.

Ueda T, Watanabe-Fukunaga R, Fukuyama H, Nagata S, Fukunaga R (2004) Mnk2 and Mnk1 are essential for constitutive and inducible phosphorylation of eukaryotic initiation factor $4 \mathrm{E}$ but not for cell growth or development. Mol Cell Biol 24:6539-6549.

van der Maaten L, Hinton G (2008) Visualizing Data using t-SNE. J Mach Learn Res 9:2579-2605.

Walsh D, Mathews MB, Mohr I (2013) Tinkering with translation: protein synthesis in virus-infected cells. Cold Spring Harb Perspect Biol 5: a012351.

Waskiewicz AJ, Flynn A, Proud CG, Cooper JA (1997) Mitogen-activated protein kinases activate the serine/threonine kinases Mnk1 and Mnk2. EMBO J 16:1909-1920.

Waskiewicz AJ, Johnson JC, Penn B, Mahalingam M, Kimball SR, Cooper JA (1999) Phosphorylation of the cap-binding protein eukaryotic translation initiation factor $4 \mathrm{E}$ by protein kinase Mnkl in vivo. Mol Cell Biol 19:1871-1880.

Yamamoto M, Sato S, Hemmi H, Hoshino K, Kaisho T, Sanjo H, Takeuchi O, Sugiyama M, Okabe M, Takeda K, Akira S (2003) Role of adaptor TRIF in the MyD88-independent toll-like receptor signaling pathway. Science 301:640-643. 